\title{
Eco-Efficiency Considerations on the End-of-Life of Consumer Electronic Products
}

\author{
J. Huisman, A. L. N. Stevels, and I. Stobbe
}

\begin{abstract}
In order to improve the eco-efficiency at the end-of-life phase of consumer electronic products, comprehensive assessments should be made. The Quotes for environmentally WEighted RecyclabiliTY and Eco-Efficiency method (QWERTY/EE) developed at the Delft University of Technology is applied to aim at minimal end-of-life treatment costs against maximal environmental recovery. In this paper, the outcomes of this eco-efficiency concept are presented based on a range of improvement options like changing shredding and separation settings, plastic recycling, glass recycling, or separate sorting of certain products. The analysis of more than $\mathbf{7 5}$ different consumer electronic products clearly shows groups in state-of-the-art recycling performance in both environmental and economic terms and a substantial distinction between the various product categories. From there, the evaluation takes place of technical improvements in relation to current best-practice recycling. Even more, with the QWERTY/EE concept it is made possible to select and rank improvement options of current and future end-of-life processing and to determine which options bring substantial environmental gain in relation to financial investments made. For glass dominated products, an increase in glass recycling results in significant environmental improvements. The same counts for separate sorting and treatment of precious metal dominated products with a relatively high precious metal content like cellular phones. However, economies of scale are a major assumption that has to be fulfilled in this case. Other conclusions and outcomes are that plastic recycling seems only eco-efficient for large housings of appliances already undergoing disassembly due to the presence of a cathode ray tube (CRT) or liquid crystal display (LCD). For small and medium-sized housings, the extra costs of plastic recycling are high in relation to the environmental improvement realized. In most cases, dedicated shredding and separation of metal dominated products does not lead to substantial environmental or economic improvements. In general, it is shown that the various options to increase the eco-efficiency of end-of-life systems lead to very mixed environmental and economic results. As a consequence, end-of-life policy strategies should be evaluated, and in some cases revised, to support and enhance the most eco-efficient improvement options. Regarding the sensitivity of the results, it is shown that although the different environmental assessment models prioritize individual materials in a different order, the results for the improvement options on a system level are pointing in the same direction, except for plastic recycling scenarios.
\end{abstract}

Manuscript received August 8, 2003; revised December 15, 2003. This work was supported in part by the Dutch Ministry of Environment, Division Non Hazardous Waste (VROM), and by The Stichting Nederlandse Verwijdering Metalektro Producten (NVMP, Dutch take-back system), and by Philips Consumer Electronics, Environmental Competence Centre (PCE-ECC)

J. Huisman is with Delft University of Technology, 2628 CE Delft, The Netherlands (e-mail: J.Huisman@io.tudelft.nl).

A. L. N. Stevels is with Delft University of Technology and Philips Consumer Electronics, Environmental Competence Centre, Eindhoven, The Netherlands (e-mail: ab.stevels@philips.com).

I. Stobbe is with the Fraunhofer Institute for Reliability and Microintegration, Environmental Engineering, Berlin, Germany (e-mail: stobbe@izm.fhg.de).

Digital Object Identifier 10.1109/TEPM.2004.832214
Index Terms-Eco-efficiency, end-of-life, recyclability.

\section{INTRODUCTION}

D UE TO increased attention on producer responsibility and take-back of products, the environmental performance of end-of-life processing as well as economic considerations have become important. Until now, a very limited number of assessments are published on both the environmental part and technoeconomical part of end-of-life processing of consumer electronic products [3], [9], [10], [17]

A comprehensive and quantified eco-efficiency approach would help support ongoing discussions about responsibilities, organization, and financing of the take-back systems [15]. But the fact that end-of-life processing can serve several (partly interlinked) goals has to be addressed as well. These goals are as follows.

- Reduction of materials going to landfill; minimizing landfill-volumes.

- Recycling of materials in order to keep maximum economical and environmental value and to prevent new material extraction.

- Reduction of emissions of environmentally relevant substances; including leaching from landfill sites and incineration slags, etc.

The methodological backgrounds of the new eco-efficiency concept are presented in the next section, including environmental and economic backgrounds, data requirements, and assumptions regarding the end-of-life chains of disposed consumer electronics. The eco-efficiency concept will be applied to a typical glass dominated product in Section III: A 17-in CRT monitor (Cathode Ray Tube). Subsequently, the evaluation of multiple products and improvement options like glass and plastic recycling will be discussed.

In this paper, a scenario or improvement option is defined as a change in end-of-life processing in relation to state-of-the-art recycling or treatment. The latter is defined as the current average end-of-life processing including collection, disassembly, shredding and separation, final waste processing, and secondary material processing as applied in the Dutch take-back system for consumer electronic products.

\section{Methodology: The QwerTy/EE CONCEPT}

\section{A. Introduction: The End-of-Life Chain}

Until now, product recyclability has mostly been calculated on a weight basis only, which is a poor yardstick from an 


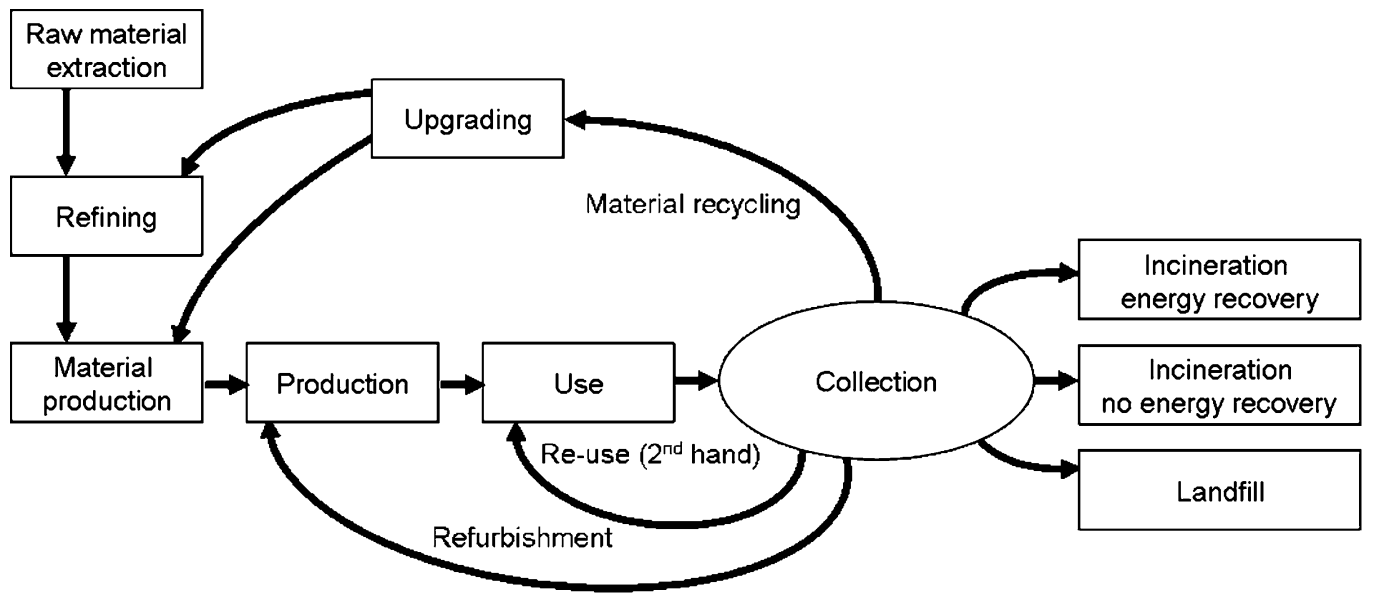

Fig. 1. Product life-cycle and end-of-life phase.

environmental perspective and it is scientifically very inaccurate and can lead to incorrect conclusions regarding the initial environmental goals. Calculations based on weight-based recyclability are likely to lead to incorrect decisions, especially when materials are present in low amounts, but with high environmental and economic values like precious metals [11]. This notion has led to the development of the Quotes for environmentally WEighted RecyclabiliTY concept (QWERTY) for calculating product recyclability on a real environmental basis. European take-back legislation for the electronics industry, the so-called Waste of Electric and Electronic Equipment (WEEE) and Restrictions on the use of Hazardous Substances (RoHS) Directives [4], [5], are primarily set up out of environmental motives. The description of treatment performance and evaluation of recyclability targets, should therefore also take place in environmental terms. Currently, this is only the case in a very limited way [9].

Before discussing the methodology being developed in detail, the starting points, boundary conditions, and elements needed for the environmental and economic calculations, are presented. In Fig. 1, a general picture of a products life-cycle and the position of the end-of-life phase is given. The starting point of the QWERTY analysis is the point of disposal by consumers. From there, the product, its components, and materials can follow different directions. The main directions are re-use, refurbishment, and material recycling as well as disposal with municipal solid waste (MSW). Whereas the QWERTY approach is primarily mentioned for material recycling, the re-use and refurbishment option are regarded as out of scope of the calculations for consumer electronics. Environmental calculations on these forms of life-time extension should precede the material recycling calculations. The environmental calculations, as shown later on in this paper, are based on life-cycle assessment (LCA), but with one important difference: the calculations are starting at the point of disposal and therefore on the end-of-life phase only.

The most important elements required for environmental validation and integral costs calculations (which are needed for the eco-efficiency part) are as follows.

- The collection and transport characteristics after discarding (Section II-D4).

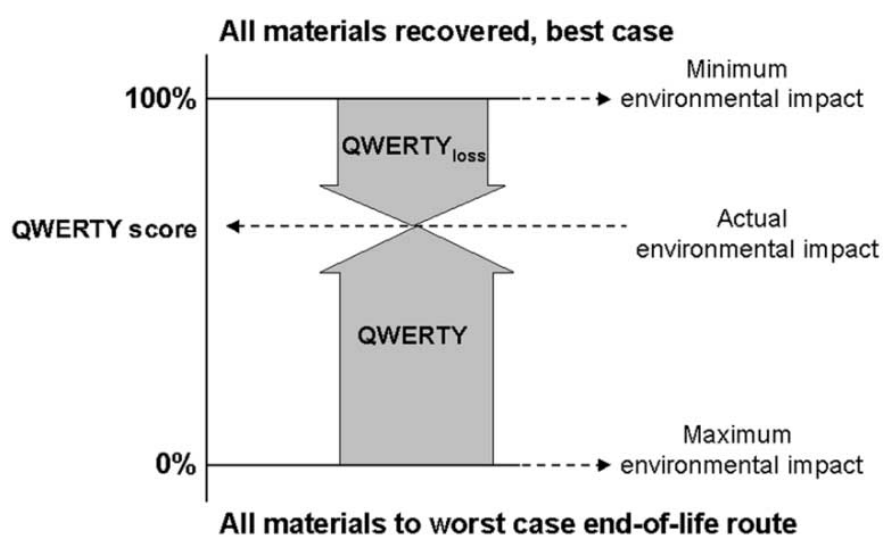

Fig. 2. Calculating QWERTY values.

- The individual behavior of products in dismantling and, or shredding and separation operations (Section II-D2).

- Modeling of the secondary material processing and disposal routes like emissions at landfill and incineration.

- An environmental validation method producing environmental scores. (Section II-D3).

\section{B. QWERTY}

Based on the modeling of the end-of-life chain, environmental and economic calculations are based on three values as displayed in Fig. 2.

1) Minimum Environmental Impact and Minimum Costs: These values are defined as all materials being recovered completely without any environmental impact or economic costs of end-of-life treatment steps, thus representing an environmental substitution value and the economic value for newly extracted and produced materials. (Usually, both are negative values, maximum environmental gain as negative environmental impacts and maximum revenues as negative costs). These values are theoretical values: in practice, there will always appear (environmental) costs connected to separation of materials, energy consumption, and transport.

2) Maximum Environmental Impact and Maximum Costs: These values for end-of-life treatment are defined 
as every material ending up in the worst possible (realistic) end-of-life route, including the environmental burden of pre-treatment: collection, transport, disassembly, and shredding and separation into fractions. The realistic end-of-life scenarios under consideration are controlled and uncontrolled landfill, incineration with or without energy recovery, and all subsequent treatment steps for material fractions, like copper, ferro, and aluminum smelting, glass oven, and plastic recycler. Also, this value cannot easily be exceeded: for instance, only under disposal conditions which are prohibited.

3) Actual Environmental Impacts and Costs: These values based on the actual environmental performance of the end-of-life scenario under consideration are compared with the two boundary conditions and expressed as percentages. This actual value is obtained by tracking the behavior of all materials over all end-of-life routes and by taking into account all costs and environmental effects connected to this. More information on this is presented in Section II-D2.

All detailed backgrounds and formulas to calculate QWERTY values can be found in [9] and [11]. In addition, data from the Fraunhofer IZM Recycling Potential Indicator (RPI) [16] is used to determine whether the scenarios assessed with the QWERTY concept are technically possible. In Section II-D3, more details follow on the environmental ingredients for the QWERTY part of the calculations; in Section II-D4, on the economic part of the calculations.

\section{Eco-Efficiency}

In order to enhance the eco-efficiency over the total end-of-life chain, the outcomes of the eco-efficiency calculations support authorities in formulating criteria for collection of disposed products and in monitoring end-of-life performance of take-back systems. It enables producers to calculate economical and environmental values on forehand. Furthermore, it supports recyclers in finding the right avenues for technology developments and investments. At last, from a consumer or society point of view, it helps getting insights in the environmental impacts per amount of money being spent, directly or indirectly.

In Fig. 3, the four main eco-efficiency directions are shown in a two-dimensional eco-efficiency graph. The $Y$-axis represents an economic index (this can be an absolute one, in euros or dollars, or a relative one, in percentages) for a single product. The $X$-axis represents an environmental index (this can also be absolute, in points or other environmental indicators, or a relative one as well). The points in this graph are possible end-of-life scenarios for one and the same product. Apart from this, changes in technology, design or system organization can be displayed. Examples of such changes are increasing plastic recycling and glass recycling, the effects of Design for Environment activities, or logistics changes. In order to achieve a higher eco-efficiency compared to current recycling scenarios, one should move into the direction of the upper right part of the graph (a plus for environment and a plus for economy). The opposite direction (minus, minus) should be avoided and the (minus, plus) and (plus, minus) should be balanced or ranked. In this paper, the choice is to use environmental points (mPts) and Euros for both axes $(€ 1.00=\$ 1.13$ at 8-8-2003).

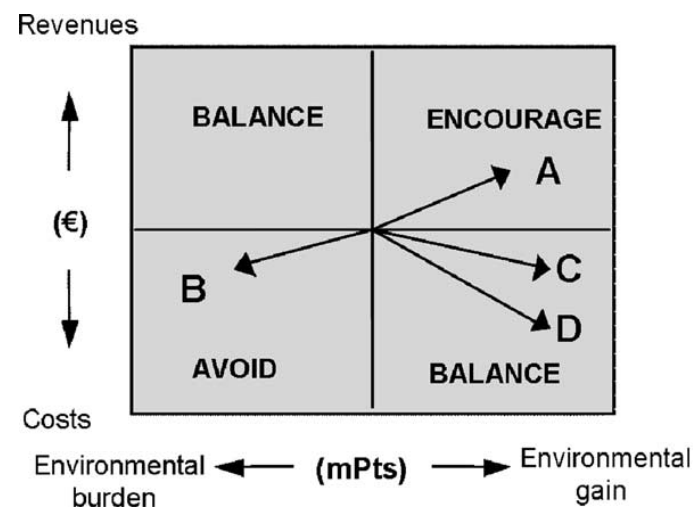

Fig. 3. Four eco-efficiency directions.

The calculations for the economic axis are done similar to the environmental calculations. The integral costs connected to the treatment of a certain product or material fraction over the end-of-life chain are determined. All elements needed for this are discussed in Section II-D.

\section{Modeling End-of-Life Chains: Assumptions and Data}

1) Assumptions: All data, results, and graphs presented in the next sections are based on the following important assumptions and starting points.

- State-of-the-art recycling is based on best available shredding and separation techniques. Shredding and separation behavior is described with distribution tables derived from [1], [2], and [9].

- Data are representing the Dutch take-back system for typically short transport distances.

- Economies of scale are realized for all examples and improvement options.

- Costs to consumers for handing in products are excluded from the integral costs.

- All graphs and results are based on the occurrence of plastics within the other fractions, mainly the residue fraction to be treated in an MSW-incineration plant.

- For all example products, chemical analysis of the printed wiring boards (PWBs) is performed. Data for all other components are obtained from environmental benchmarks [12]. The two combined result in full product compositions.

- For the other products without chemical analysis of PWBs, good estimates are available based on the types of PWB materials, the level of integration of components, and the amounts and types of components attached to the boards [12].

- The Eco-Indicator'99, Philips Best-Estimate, Hierarchic Perspective, Average Weighting set, weighting factor Resource Depletion-Minerals adjusted to $5 \%$, is used as a default environmental assessment model [9]. More details on the application of single environmental scores, the weighting set, and other LCA characteristics follow in Section II-D3.

- All fractions sent to a subsequent process fall under the acceptance criteria applicable for this process or operation. 


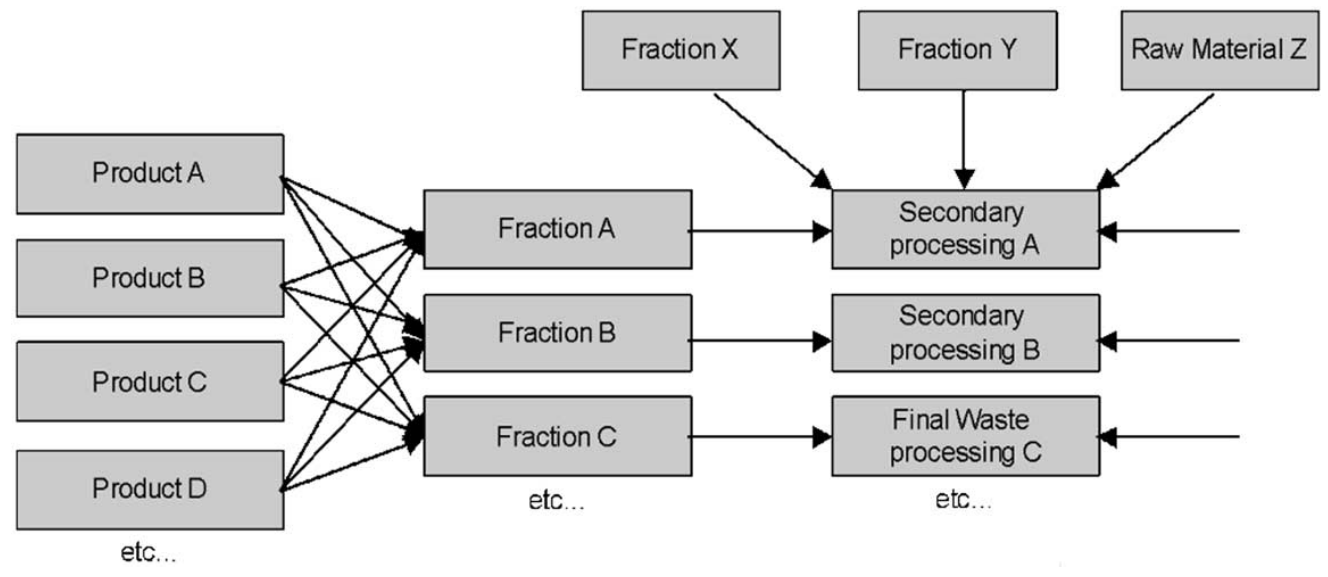

Fig. 4. Double ensemble issue.

2) The Double Ensemble Issue: In many cases, the environmental performance of individual products in end-of-life processing, as illustrated in Fig. 2, cannot be determined as such. The reason is that no individual products are treated as such, but rather as material streams as a result of shredding and separation or disassembly operations (not for reuse of remanufacturing purposes). This is referred to as an ensemble issue. The product streams are transformed into fractions to be treated in a subsequent process, a secondary material processor, or final waste processor. In fact, another ensemble issue occurs here. A copper smelter, for instance, does not treat single fractions but fractions of multiple sources. A combined copper smelter, for instance, takes in both fractions from secondary origin as well as primary materials from ore. This double ensemble issue is displayed in Fig. 4.

Fig. 4 is important for the quantification of environmental and economic performance of individual products in end-of-life treatment. The aim of this paper is not only to determine system performance of large product streams and multiple environmental processing steps as origin for the environmental and economic calculations, but also the performance of individual products and materials in given product and material streams and in take-back systems as a whole. This product perspective helps evaluate take-back systems. In practice, it is impossible to track each individual product and material in the steps drawn in Fig. 3. As a consequence, it is not possible to describe the behavior of single products or materials in a complex end-of-life system based on actual behavior.

It is, however, possible to make a first-order estimate on the double ensemble issue. This is presented in Fig. 5. (In fact, there are multiple materials in one product, multiple products in one product stream, multiple product streams are converted to multiple fractions, and multiple fractions are treated by multiple processing options). The solution or first-order estimate for the double ensemble issue is to use average distribution tables for certain settings in shredding and separation for a certain product stream. This includes the description of the distribution of materials over the end-of-life chain. In detail, this distribution of all materials over the various fractions results in contributions to fractions which on their turn are assumed to be treated as real fractions in subsequent secondary material or final waste processing (see, for instance, Table II). The distribution tables are a first-order estimate of the chance of appearance of a certain material in a certain fraction. When calculated for all materials within a product, the contribution of the product as a whole to the resulting fractions is obtained. These imaginary contributions or fractions are treated as real fractions again in subsequent processing steps. In this secondary or final waste processing, again, average distribution tables are used to describe the amounts of materials respectively recovered, ending up in other new fractions sent toward other processing (like slags), or emitted to air, water, or soil. Mass balancing of all materials present in the product under consideration is applied, describing the estimated routes of all materials in all processing steps involved.

Due to the focus on the performance of individual products in this paper, calculations are starting with the behavior of single products and not with product streams. As a consequence, both environmental as economic performance for all materials in a certain product under investigation over all relevant end-of-life processing steps can be related to this individual product. Subsequently, the contribution of many individual products to a total system can be determined. This choice and solution with respect to the double ensemble issue is crucial and is resulting in better understanding of the behavior of products in complex end-of-life systems and the aimed alignment of technology, design, and policy. Due to the importance of the tables, the subsequent distribution tables are checked by other experts in [1] and [2] and published in [9].

3) Environmental Assessment Models and Data: The QWERTY calculations require environmental values. These values can be derived from any comprehensive environmental assessment model that produces these scores, but also methods focusing on a single environmental effect, like for instance, eco toxicity or resource depletion, can be used. The default method applied in this paper is the Eco-Indicator'99 method, a damage-oriented LCA method. The approach is also called a top-down LCA method since all contributions to all environmental effects are translated to actual damage inflicted on eco-system quality, human health, and resource depletion [7], [8]. In addition to the default choice, other methods are integrated in the QWERTY/EE calculations to evaluate the environmental outcomes. It is possible to evaluate based on single environmental themes, like for instance on greenhouse 


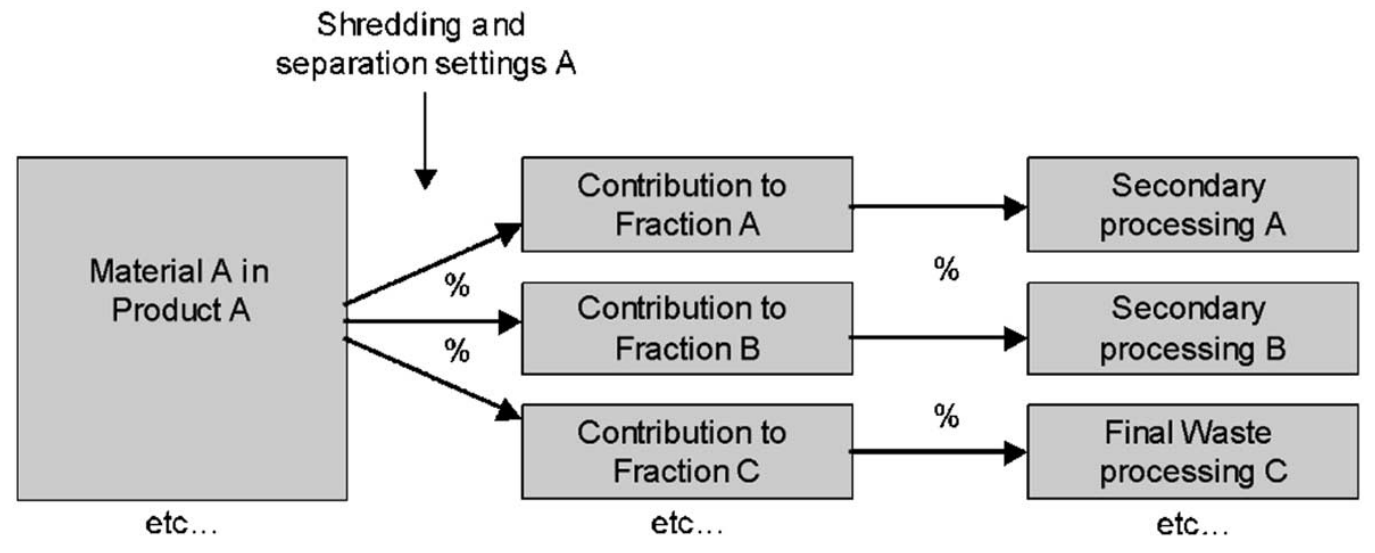

Fig. 5. Solution to the double ensemble issue.

effect alone. With this, the disadvantages of applying a final weighting step as enumerated below are reduced, but it limits the relevance of results to single environmental themes only.

Further considerations with respect to the use of LCA methods and methodologies for providing environmental values are that in LCA, there is always a subjective evaluation step involved to weigh different environmental themes and to produce a single end-point score. This is inherent to aggregated environmental scores of any kind. One reason for choosing the Eco-Indicator'99 method is that, compared to other LCA methods, it is the most transparent one regarding influence of different environmental perspectives and opinions of all factors that influence the final end-point score (and not only the final weighting step). Furthermore, the starting point of the QWERTY concept is not the same compared to LCA. The QWERTY analysis starts at the point of disposal until the end of the end-of-life phase, while LCA methods regard the full life-cycle of products, hence, different system boundaries and allocation rules apply. Due to this different starting point, the QWERTY concept regards materials that are recycled as preventing extra environmental load (so negative values appear for recycled materials) due to avoidance of new raw material extraction. As a results of this choice, many problems with allocation and the definition of system boundaries are prevented [9].

An important requirement is an environmental database [12] providing environmental values for all relevant end-of-life processing steps and materials. For all relevant processing of materials, the mass and energy balances must be transferred to corresponding environmental values. Especially for the end-of-life phase of products, there are usually many data gaps within current LCA-databases. Therefore, additional data on all processes relevant for end-of-life treatment of consumer electronics is gathered and included in the database. These environmental data can be found in [9] and are summarized here.

- Transport distances, way of transport and destinations, energy needed for collection, and sorting.

- Energy needed for shredding and separation.

- Environmental impacts of incineration, including energy recovery effects.

- Environmental impacts of controlled and uncontrolled landfill.
- Environmental impacts at metal smelter operations, including emissions, energy needed, and recovery percentages.

- Environmental impacts of other secondary material processing like plastic recycling, CRT glass recycling, ceramic industry, building industry, cement kiln, etc.

Under the default method applied, the Eco-Indicator '99, different perspectives exist for the environmental validation in general. This is represented by different weighting sets for the various environmental effect categories (like greenhouse effect, ozone layer depletion, and resource depletion) in the LCA calculations. As mentioned in Section II-D2, the Eco-Indicator'99, Philips Best-Estimate, Hierarchic Perspective, Average Weighting set, weighting factor Resource Depletion-Minerals adjusted to 5\%, is used as a default. The Philips Best-Estimate refers to an update of the characterization factors connected to a few metals relevant for electronic products (solder materials). These values are updated by new research regarding the fate and exposure of the metals concerned in the environment [9]. The Hierarchic Perspective-Average Weighting set refers to the commonly used set for weighting different environmental themes. More information on the application of different weighting sets can be found in [7]. The adjustment of the specific characterization factors for the environmental theme Resource Depletion-Minerals is due to the use of the so-called Surplus Energy approach in the Eco-Indicator'99 method to estimate the extra energy needed for new material extraction in relation to decreasing average ore concentrations. This Eco-Indicator'99 approach is different from more traditional approaches based on the quotient of global metal consumption versus reserve base. The determination of the reserve base of minerals is subject to many different interpretations. From a methodological point of view, with the surplus energy method, the discussion on how much metal reserves are still available is avoided. The extraction and connected speed of increasing energy needed to acquire the same amount of metal over time is regarded as a better reflection of environmental damage. However, in practice, for some metals the uncertainty in average ore concentrations versus time/amounts extracted is very high. This has lead to overestimates of the mineral depletion values in particular for gold and nickel, which are of relevance for electronics. The 
above effect is one of the reasons to lower the weighting factor for resource depletion of minerals to $5 \%$ as. The uncertainty in resource depletion factors in the Eco-Indicator' 99 methodology is confirmed by [13]. The decrease in weighting factor is applied to keep the resource depletion aspect included in the methodology on one hand, and to avoid overestimation on the other hand. Furthermore, the adjustment results in a similar ranking of materials as compared with traditional consumption versus reserve base methods [14]. The sensitivity of the results as a result of this choice is checked in [9]. In the conclusions and discussion presented in Section V-A and V-B of this paper, a sensitivity analysis is also performed by showing the influence of using a different LCA method.

4) Economic Data: Many of the data to determine the $Y$-axis of Fig. 2 are derived from the Fraunhofer RPI tool [16] and the TU Delft/Philips Product Material Recycling Cost Model (PMRCM) [3]. Further data is made available by Dutch and German recyclers and waste processing installations [9]. Included are:

- Sorting, registering, transportation, and buffer storage costs.

- Integral costs for shredding and separation.

- Costs at primary copper smelting including treatment charges, analysis and administration costs, as well as price adjustments percentages for recovered metals. Also included are refining charges and unit deductions for copper, silver, gold, and palladium (including concentration dependencies) and costs for penalty elements like arsenic, chlorine, mercury, lead, antimony, and bismuth (concentration dependent).

- Costs at ferro and aluminum smelter processes.

- Costs at incineration sites, both MSW incineration and special waste incineration, also including charges for all environmentally relevant materials (concentration dependent).

- Costs at landfill sites, also including charges for all environmental relevant elements occurring in disposed consumer electronics (concentration dependent).

- Costs for plastic recycling including cleaning and upgrading, color sorting.

- Disassembly costs based on disassembly times for standard operations.

- Revenues paid for all recovered materials.

With the environmental and economic modeling of the end-of-life chain as presented in Fig. 1, the values for both axes in Fig. 3 are calculated. In the next section, an example will be given on how this is performed in practice.

\section{EXAMPLE: A GLASS DOMINATED PRODUCT}

\section{A. Product Data, Pre-Treatment, Shredding, and Separation}

The following steps are taken to conduct the eco-efficiency analysis.

- Product data are gathered and shredding and separation behavior is modeled.

- Contributions of materials to the QWERTY values are determined.
TABLE I

PRODUCT COMPOSITION 17-in CRT MONITOR

\begin{tabular}{lll}
\hline Material & Weight $(\mathrm{g})$ & Weight\% \\
\hline Aluminum & 48,55 & $0,33 \%$ \\
Copper & 892,15 & $6,09 \%$ \\
Ferro & 1324,08 & $9,04 \%$ \\
Glass & 9392,50 & $64,1 \%$ \\
Plastics & 2606,62 & $17,8 \%$ \\
$\mathrm{Ag}$ & 0,16 & $11 \mathrm{ppm}$ \\
$\mathrm{Au}$ & 0,01 & $0,7 \mathrm{ppm}$ \\
Pd & 0,00 & $0,3 \mathrm{ppm}$ \\
Other & 385,22 & $2,63 \%$ \\
\hline Total & 14649,30 & $100 \%$ \\
\hline
\end{tabular}

TABLE II

Fraction COMPoSItIons From STATE-OF-THE-ART SHREDDING AND SEPARATION

\begin{tabular}{lllllll}
\hline Fraction & Ferro $(\mathbf{g})$ & $\begin{array}{l}\text { Aluminium } \\
(\mathbf{g})\end{array}$ & $\begin{array}{l}\text { Copper } \\
(\mathbf{g})\end{array}$ & $\begin{array}{l}\text { Glass } \\
(\mathbf{g})\end{array}$ & $\begin{array}{l}\text { Plastics } \\
(\mathbf{g})\end{array}$ & $\begin{array}{l}\text { Residue } \\
(\mathbf{g})\end{array}$ \\
\hline Aluminium & 0,25 & 40,09 & 7,28 & 0,00 & 0,00 & 0,93 \\
Copper & $\mathbf{8 , 3 9}$ & 44,61 & 6997,75 & 0,00 & 0,00 & 141,4 \\
Ferro & 1258 & 26,48 & 26,48 & 0,00 & 0,00 & 13,24 \\
Glass & 46,96 & 46,96 & $\mathbf{9 3 , 9 3}$ & $\mathbf{9 1 5 8}$ & 0,00 & 46,96 \\
Plastics & 31,54 & 13,03 & 260,7 & 0,00 & 1895 & 406,4 \\
Ag & 0,000 & 0,000 & 0,138 & 0,000 & 0,000 & 0,025 \\
Au & 0,000 & 0,000 & 0,0088 & 0,000 & 0,000 & 0,0010 \\
Pd & 0,000 & 0,000 & 0,0033 & 0,000 & 0,000 & 0,0004 \\
Other & 1,34 & 1,47 & 125,1 & 123,1 & 58,03 & 76,26 \\
\hline Fraction & $\mathbf{1 3 4 6}$ & $\mathbf{1 7 2 , 6}$ & $\mathbf{1 2 1 1}$ & $\mathbf{9 2 8 1}$ & $\mathbf{1 9 5 3}$ & $\mathbf{6 8 5 , 2}$ \\
Weight & & & & & & \\
\hline Fraction \% & $\mathbf{9 , 2 \%}$ & $\mathbf{1 , 2 \%}$ & $\mathbf{8 , 3 \%}$ & $\mathbf{6 3 , 4 \%}$ & $\mathbf{1 3 , 3 \%}$ & $\mathbf{4 , 7 \%}$ \\
\hline
\end{tabular}

- Different environmental scenarios are calculated such as recycling, incineration, landfill, etc.

- Integral costs per stage of the end-of-life chain are calculated.

- Different cost scenarios are calculated such as recycling, incineration, landfill, etc.

- The eco-efficiency graphs similar to Fig. 3 are determined

- The eco-efficiency outcomes for improvement options like plastic recycling and glass recycling are calculated.

In this section, a 17-in CRT monitor from 2002 will be discussed as a typical example of a glass dominated product. In addition, the PWB compositions of this product are chemically analyzed. In Table I, the resulting product composition is given. The most important characteristic is obviously the high glass content, which is $9.4 \mathrm{~kg}$ on a total product weight of $14.7 \mathrm{~kg}$. The precious metal content in this well-developed product is $8 \mathrm{ppm}$ for gold, $133 \mathrm{ppm}$ for silver and $5 \mathrm{ppm}$ for palladium over the total amount of the electronic fraction (PWBs and wiring). On the total product weight, this is $11 \mathrm{ppm}$ for Silver, $0.7 \mathrm{ppm}$ for gold and $0.25 \mathrm{ppm}$ for palladium.

For CRT-containing products, disassembly of the CRT and the plastic front and back covers is applied. The remainder is shredded after removing the electron gun, the deflection coil, the degaussing coil, and the cabling and wiring. This results in six fractions. In Fig. 6, these steps are displayed.

The resulting compositions are displayed in Table II.

The default destinations of the fractions are respectively ferro smelting, aluminum smelting, copper smelting, and incineration with energy recovery of the plastic and residue fraction. For 


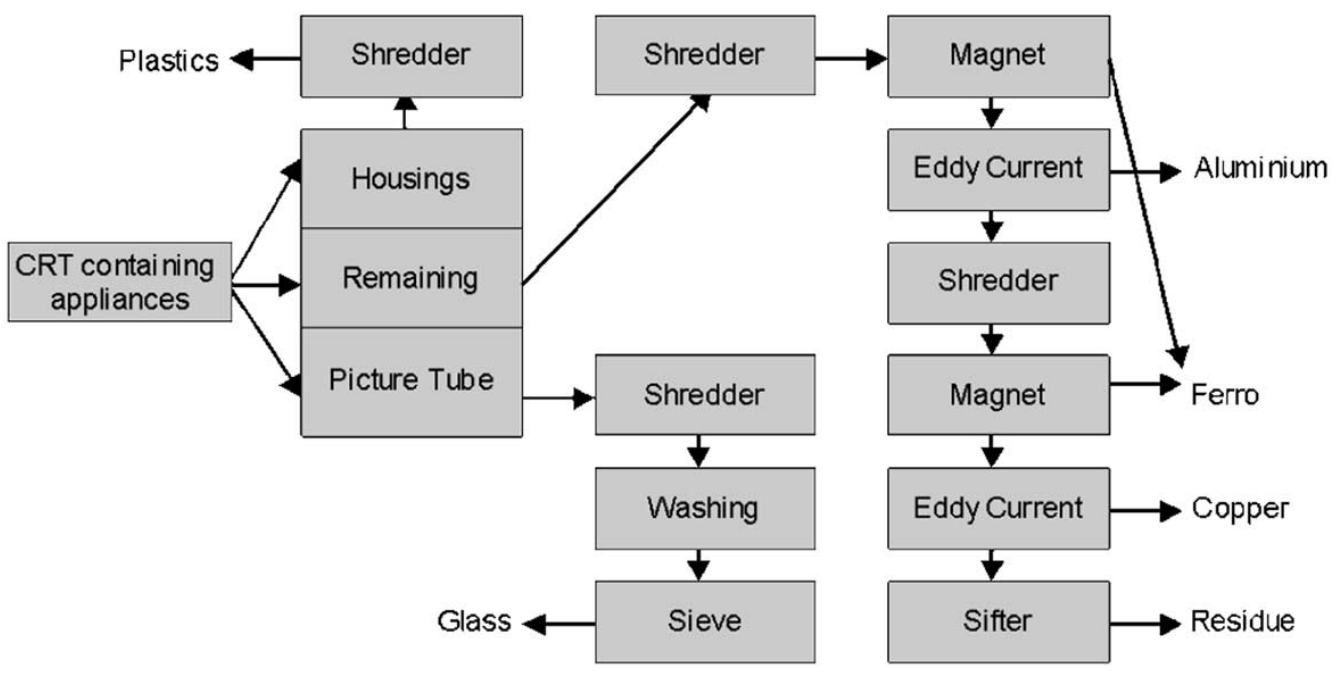

Fig. 6. Shredding and separation of CRT- containing appliances.

QWERTY $43,4 \%$

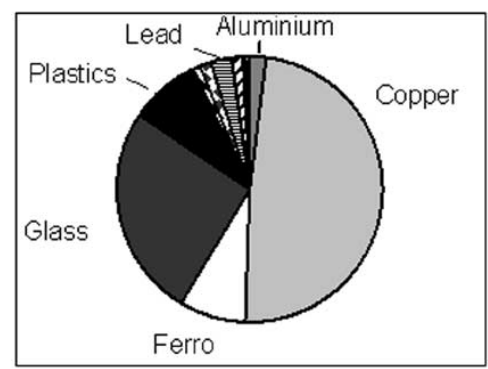

Fig. 7. Contribution of materials to the QWERTY values recovered/lost.

the glass fraction, this table represents the 2001 average situation for the Netherlands with only $15 \%$ recycling of old to new CRT glass, $40 \%$ to uncontrolled landfill, $35 \%$ to the building industry, and $10 \%$ to the ceramic industry. The environmental performance of the current settings will be discussed in the next section.

\section{B. Environmental Performance}

Fig. 7 displays the QWERTY scores of the 17-in Monitor. Note that this "environmental recyclability graph" is completely different compared to the material composition on a weight basis as represented by Table I. The two pies together represent the QWERTY definition. In this graph, copper plays a more important role compared to its weight (Table I), both to the QWERTY loss and QWERTY gained percentages. The contribution of glass is much smaller compared to the weight percentage of $64 \%$ in Table I. The QWERTY value under state-of-the-art recycling is $43,4 \%$.

Besides the state-of-art recycling scenario as displayed in Fig. 7, the environmental behavior of the product within other scenarios also can be displayed. In Fig. 8, the environmental performance of the 17-in CRT monitor within all end-of-life scenarios (the product as a whole goes into one scenario) is shown. The third recycling bar is the average Dutch state-of-the-art recycling scenario. Note that recovery of copper adds the most to the recovered environmental value. Also, an important conclusion is that although state-of-the-art recycling is applied,
QWERTY loss $56,6 \%$

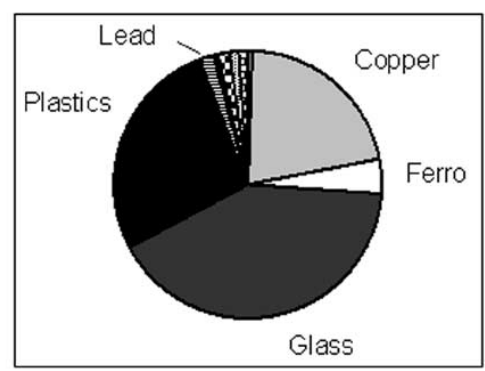

the environmental recovery is far from the best-case scenario (first bar) primarily due to the glass and plastics content not being recycled. To some extent, energy required for end-of-life treatment and environmental impacts of transport play a role as well.

\section{Costs and Revenues}

In this section, the economic performance of the 17-in CRT monitor is discussed. The costs per end-of-life stage are represented in Table III. In contrast to the environmental impacts per stage, the highest costs are caused by, respectively: disassembly, sorting and handling, collection, shredding, and separation. The total disassembly time is calculated at 285 seconds. The costs presented are excluding the costs for consumers to hand in their products. In total, some material value $(€ 1.47)$ is regained at the secondary material processors, but this is substantially lower than the total costs for all operations $(€ 7.41)$ to which the costs for collection and recycler are the highest $(€ 5.17)$. Again, the costs to consumers for handing in products at municipalities or retailers are excluded. These additional costs are estimated at $€ 3.03$ per 17 -in CRT monitor.

Fig. 9 shows the economic equivalent of Fig. 8. (A minus means a revenue or negative cost). Besides the state-of-art recycling scenario (third bar), the economic behavior of the product within other scenarios can also be displayed. An important conclusion is that although state-of-the-art recycling is applied, the economic recovery (in fact, only net costs are 


\section{Environmental burden (mPt)}

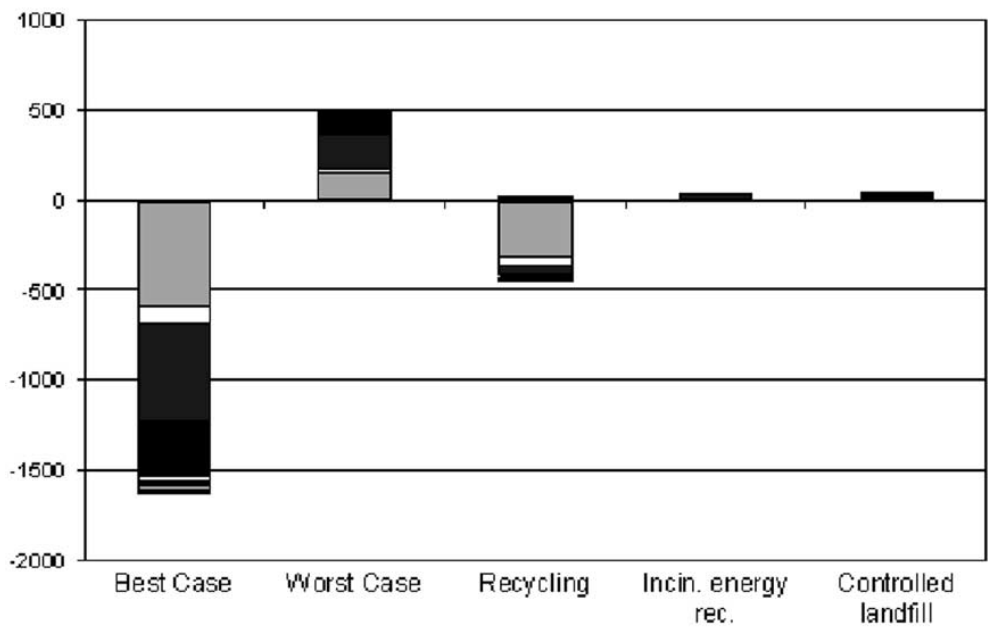

Emvironmental gain (mPt)

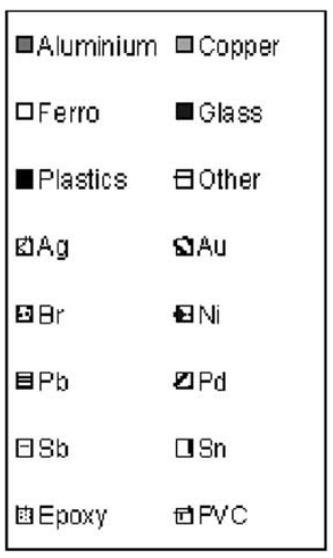

Fig. 8. Environmental scenarios.

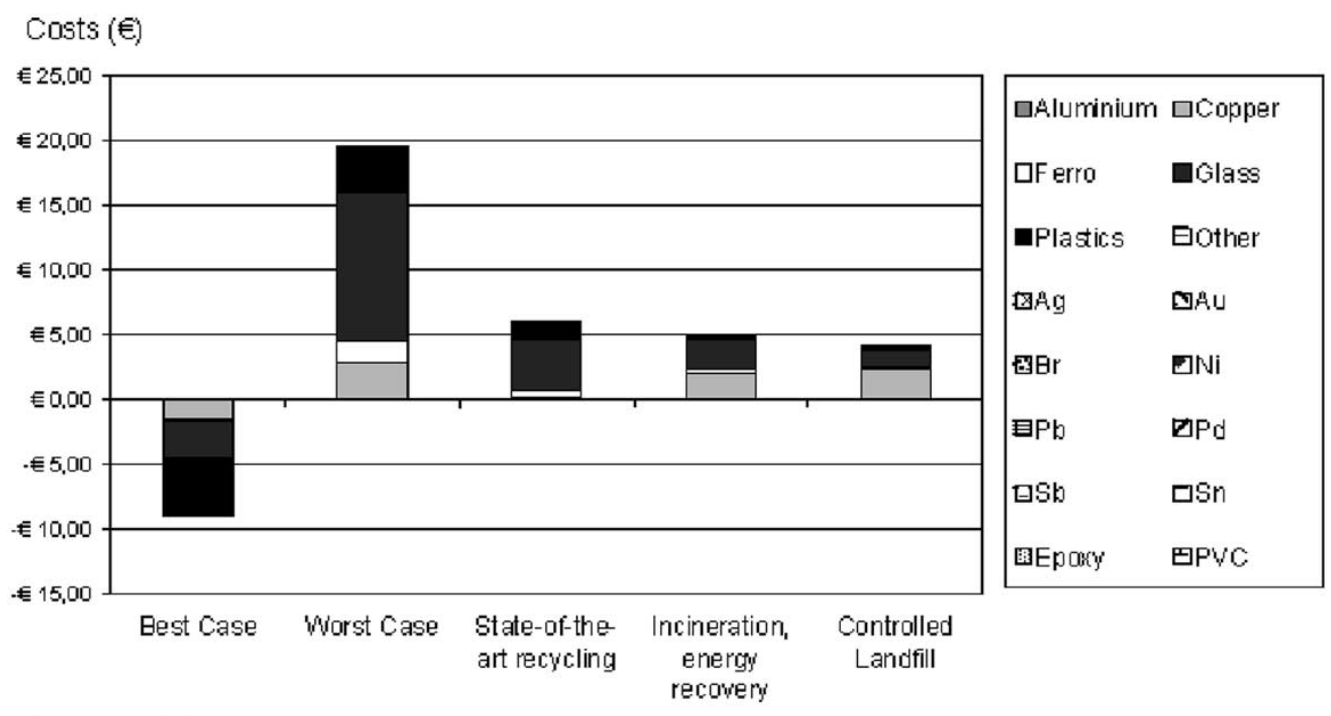

Revenues (€)

Fig. 9. Cost scenarios.

TABLE III

Integral Costs Per END-OF-Life Stage

\begin{tabular}{llll}
\hline End-of-life stage & Integral costs & Costs & Revenues \\
\hline Transport and collection & $€ 0,81$ & $€ 0,81$ & $€ 0,00$ \\
Disassembly & $€ 2,85$ & $€ 2,85$ & $€ 0,00$ \\
Shredding and separation & $€ 0,48$ & $€ 0,48$ & $€ 0,00$ \\
Sorting and handling & $€ 1,03$ & $€ 1,03$ & $€ 0,00$ \\
Incineration, energy recovery & $€ 0,13$ & $€ 0,13$ & $€ 0,00$ \\
Landfill uncontrolled & $€ 0,24$ & $€ 0,24$ & $€ 0,00$ \\
Building industry & $€ 0,34$ & $€ 0,34$ & $€ 0,00$ \\
Ceramic industry & $€ 0,08$ & $€ 0,12$ & $-€ 0,04$ \\
Copper smelter & $-€ 0,26$ & $€ 0,74$ & $-€ 1,00$ \\
Aluminum smelter & $€ 0,06$ & $€ 0,11$ & $-€ 0,05$ \\
Ferro smelter & $-€ 0,07$ & $€ 0,06$ & $-€ 0,12$ \\
Glass furnace & $€ 0,27$ & $€ 0,52$ & $-€ 0,25$ \\
\hline Total & $€ 5,96$ & $€ 7,41$ & $-€ \mathbf{1 , 4 5}$ \\
\hline
\end{tabular}

realized) is far from the best-case scenario, in this case, mainly due to the disassembly and collection costs.

\section{Eco-Efficiency Graphs}

1) Current Treatment Within the Dutch Take-Back System: In this section, the economic and environmental data are brought together in the eco-efficiency graph of Fig. 10. With this graph, the effect of increasing collection rates is visualized. The arrow nr. 1 in Fig. 10 shows that with the change from $0 \%$ collection toward $60 \%$ collection (and $31 \%$ incineration and $9 \%$ landfill) results in higher environmental gains against slightly lower costs for the take-back system as a whole. If it would be possible to collect $100 \%$ of the discarded products (arrow nr. 2), then a significant increase in environmental gain is realized against higher costs. The total 


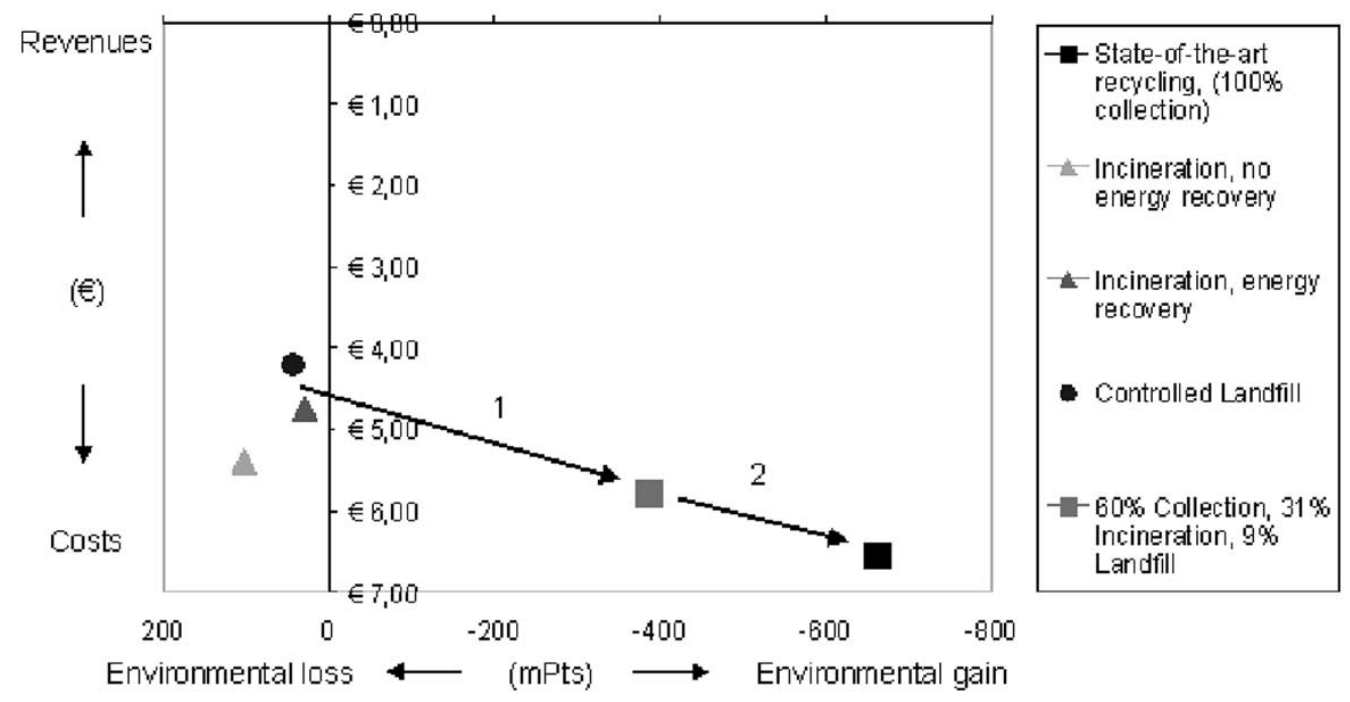

Fig. 10. Eco-efficiency of all relevant end-of-life options.

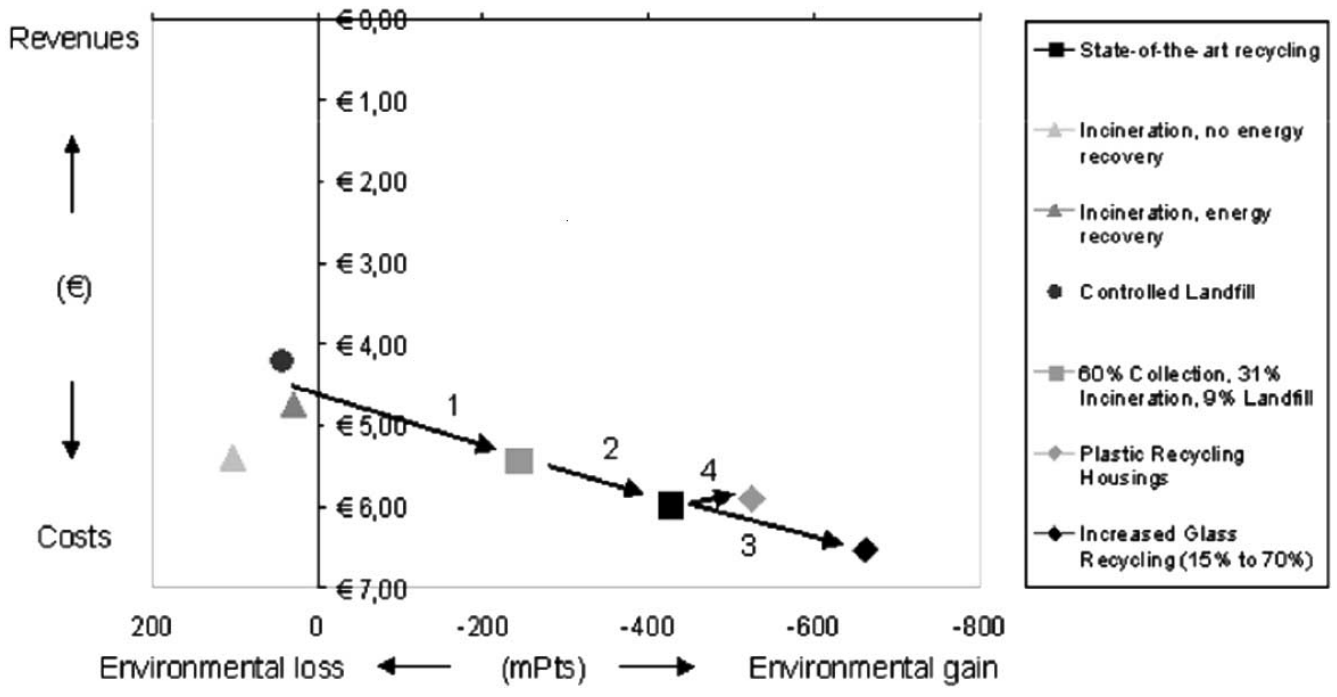

Fig. 11. Eco-efficiency of increased glass and plastic recycling.

costs for the system are then increasing from $€ 5.42$ per 17 -in CRT monitor to $(14.7 \mathrm{~kg})$ to $€ 5.95$.

2) Increasing Glass and Plastic Recycling: One option to increase both the environmental and economic recovery from metal dominated products is to increase CRT glass recycling. The maximum percentages that can technologically be achieved are estimated at $70 \%$ recovery of glass back to CRT glass (screen-to-screen and cone-to-cone glass), $20 \%$ to the ceramic industry (replacement of Feldspar), and 10\% to the building industry (replacement of sand). The resulting eco-efficiency direction is displayed with the fourth arrow in Fig. 11. An assumption here is that there is a demand at the glass producers for secondary material, which is often not the case due to technical constraints, immature markets, and varying compositions of secondary glass.

Fig. 11 shows a substantial improvement in environmental performance for increased glass recycling (see arrow nr. 3 in Fig. 11: from -425 to $-661 \mathrm{mPts}$ ). From a cost perspective, there is an increase from $€ 5.95$ to $€ 6.54$ per product.
Another option is to increase plastic recycling. Instead of incineration with energy recovery of the plastic fraction, the recycling of $1.9 \mathrm{~kg}$ of the front and back covers is taken into account. The resulting eco-efficiency direction is also displayed in Fig. 11 with arrow nr. 4. The result of this plastics recycling is an environmental improvement of -425 to $-525 \mathrm{mPts}$ against almost the same costs (from $€ 5.95$ to $€ 5.88$ ) as the original scenario with incineration plus energy recovery.

\section{Evaluation of Multiple Products and Scenarios}

\section{A. Eco-Efficiency of Multiple Products}

Besides the example product discussed in the previous section, the eco-efficiency of other products and product categories also can be calculated. Around 75 different product compositions from the Philips Environmental Benchmark reports [12] are evaluated. In this paragraph, the following eco-efficiency graphs are presented for the next four product categories. 


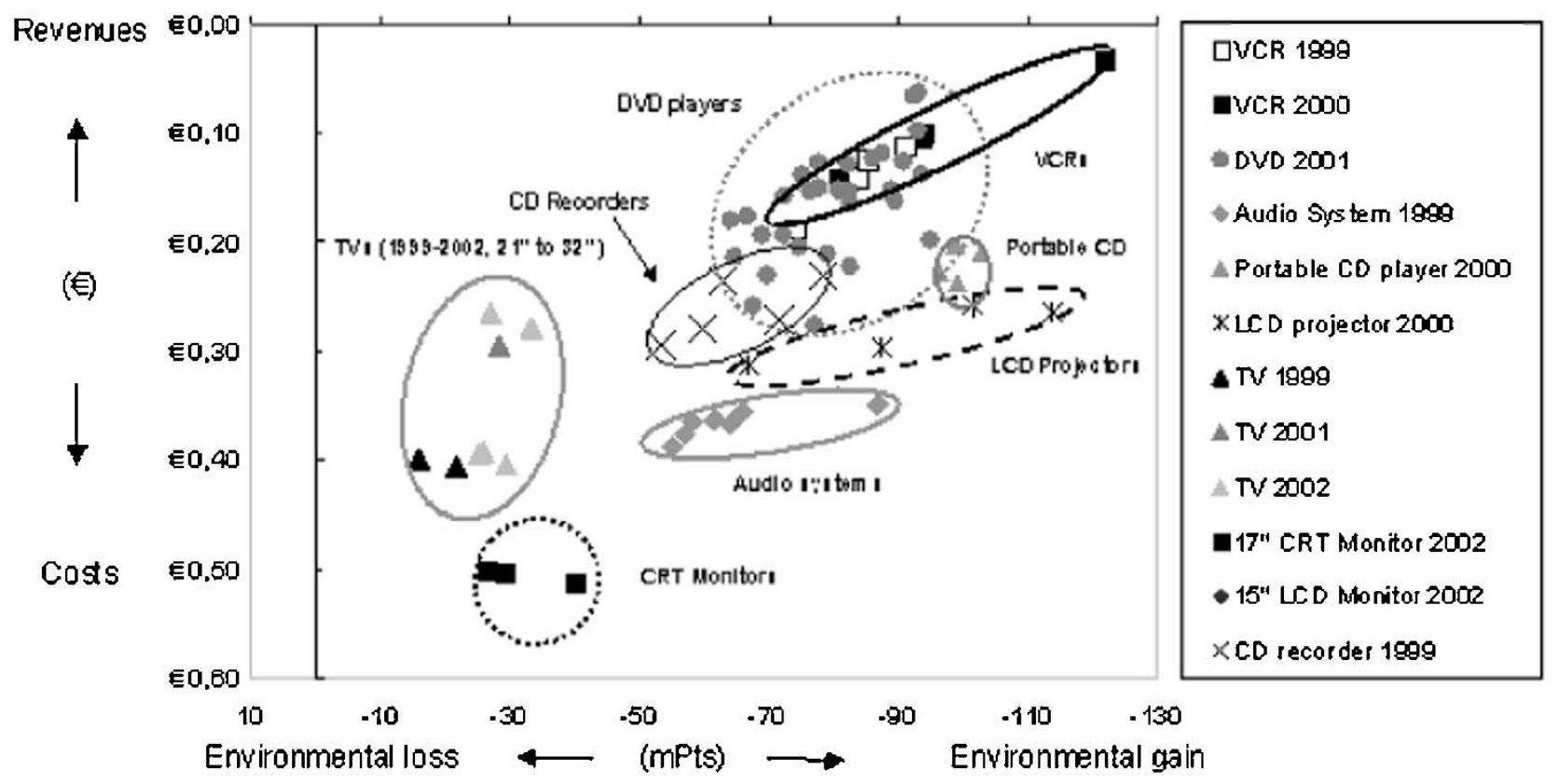

Fig. 12. Eco-efficiency of state-of-the-art recycling of various (large) products.

- Glass dominated products that are all products containing a picture tube (this also means exclusion of LCD screens (Section IV-B)

- Plastic dominated products, which are all products with a plastic content above 50\% (Section IV-C), but excluding the precious metal dominated products.

- Metal dominated products, which are in general all products with a metal housing, but no picture tube and also excluding the precious metal dominated products. The metal content (copper, aluminum, and ferro) must be greater than $50 \%$.

- Precious metal dominated products: all products without a picture tube for which the total gold plus palladium content exceeds $50 \mathrm{ppm}$ (parts per million, $50 \mathrm{ppm}=$ $0.005 \%)$.

In Fig. 12, the QWERTY/EE results for all these products are summarized in one graph. Despite the relatively low amount of products per type/year, clear groups of similar products are formed. The economic and environmental performance of the larger products appears in this graph. Not displayed are cellular phones, which have a relatively high yield per product and high environmental recovery values until $€ 4.00$ and $1000 \mathrm{mPts}$ per $\mathrm{kg}$ treated. Other categories are: LCD-projectors ranging from 60 to $120 \mathrm{mPts}$ recovered environmental value and costs around $€ 0.35$ per product; CRT Monitors (around $€ 0.50,40 \mathrm{mPts}$ per kg); Audio systems (around $€ 0.35$, and $40 \mathrm{mPts}$ per $\mathrm{kg}$ ); and TVs (around $€ 0.30$, and $25 \mathrm{mPts}$ recovered environmental value); DVD players and VCRs around $€ 0.15$ and $90 \mathrm{mPts}$ per $\mathrm{kg}$.

\section{B. Eco-Efficiency of Glass Dominated Products}

The first product category to be evaluated is that of the glass dominated products. From this category, 15 different TVs and
CRT monitors are taken with production years between 1999 and 2002 and with screen sizes between 15-in and 28-in. Disassembly times are measured and included in all scenarios and are known from the Philips Consumer Electronics Environmental Benchmark reports [12]. The corresponding costs are also included for the default state-of-the-art recycling scenario, while also without plastic recycling, the CRTs must be disassembled. LCD monitors form a different group compared to the CRT containing products and are not evaluated here. In fact, they are not in the glass dominated area of Fig. 11, but around the middle of the metal dominated area and the plastic dominated area.

A key question for the glass-dominated products is what the results of plastic and glass recycling are in relation to the state-of-the-art recycling scenario. Both options are assumed to be best case scenarios and are calculated under the assumptions and conditions of Section II-D1. The calculations for both the increased glass and plastic recycling are presented in Fig. 13.

In Fig. 13, a clear result is generated. The plastic recycling of large housings which are already disassembled (no extra disassembly costs accounted to the plastics), leads in all cases to a small environmental improvement of around $8 \mathrm{mPts}$ per $\mathrm{kg}$ of product weight and to a decrease in integral costs of around $€ 0.02$ per $\mathrm{kg}$. The increased glass recycling leads in all cases to a relatively large environmental improvement of around $14 \mathrm{mPts} / \mathrm{kg}$ compared to the plastic recycling scenario against a cost increase of $€ 0.08$ per kg. Although the results per kg are relatively small, they appear for all products under consideration and they are in line with the results of the example 17-in CRT monitor in Section III. It has to be noted that the results presented are valid for best case plastic recycling and glass recycling with allocating all disassembly costs to the glass. In practice, however, plastic recycling is often not possible due to the presence of flame-retardants or other contaminations or due to a lack of markets for secondary plastics. 


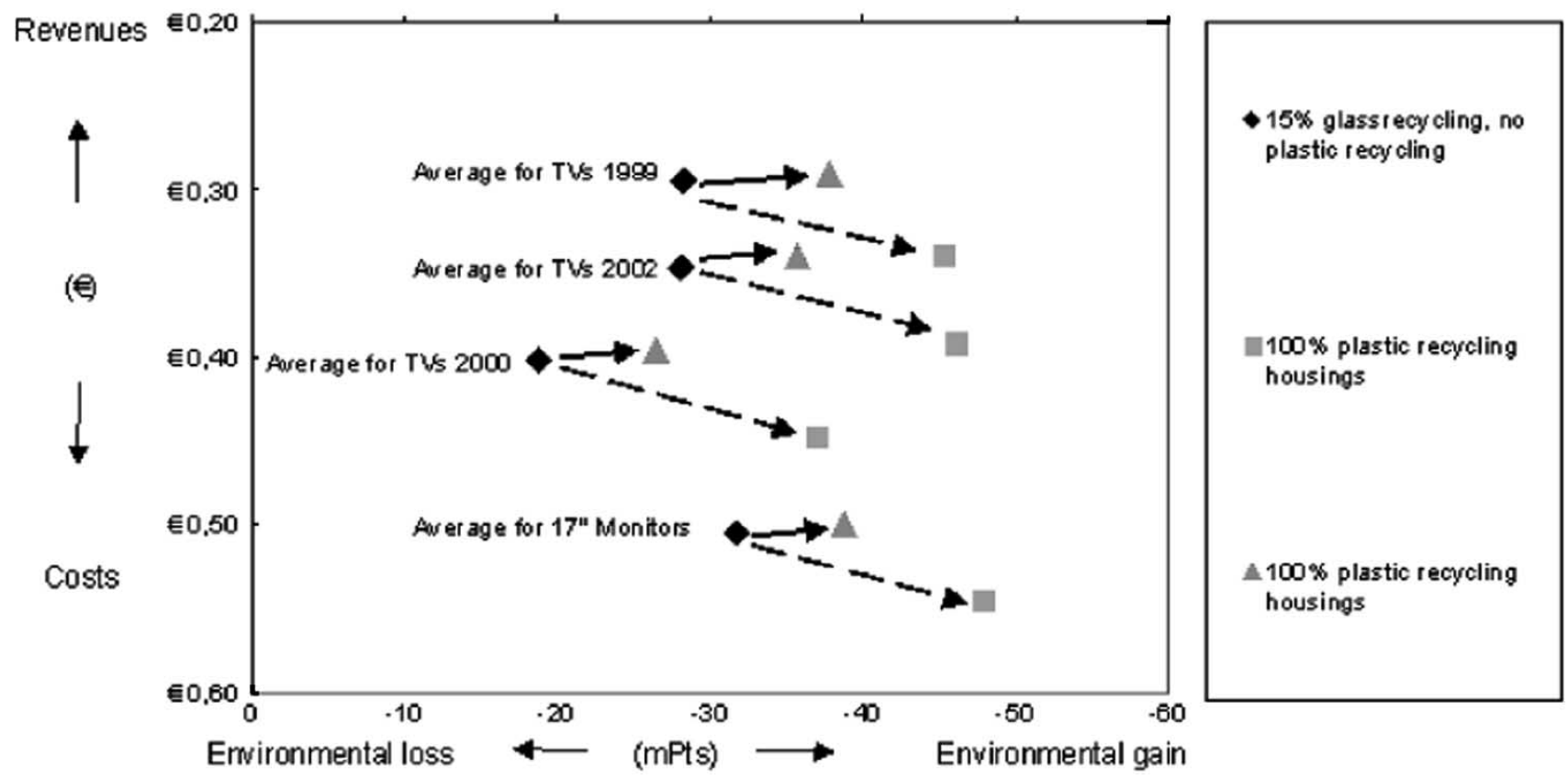

Fig. 13. Eco-efficiency per kg of glass and plastic recycling of CRT containing products.

\section{Eco-Efficiency of Plastic Dominated Products}

The second product category to be evaluated is that of plastic dominated products. As examples, 16 different audio systems, portable CD players, and fax machines are used. These products chosen have a large variety in product weight. The audio systems (7 pieces) are from the year 1999 and weigh around $20 \mathrm{~kg}$; the fax machines (4 pieces) are from the year 1999 and weigh around $5 \mathrm{~kg}$; the portable CD players (4 pieces) from the year 2000 and weigh around $0.5 \mathrm{~kg}$ [12]. The portable CD players have very similar product compositions. The fax machines, however, are very different. In two of them, a scanner and phone is also included. The audio systems also have rather different product compositions, especially in PWB weight and sophistication.

A key question for the plastic dominated products is about the relation between the weight of the plastic housings of the above products and the eco-efficiency of the corresponding improvement avenue: plastic recycling. A best case scenario is assumed for the plastic recycling of housings of the three product types. This means plastic recycling under economies of scale and under the assumptions that the plastic housings can be gathered without any contaminations, which is not the case for most of the products. The portable CD player and the audio systems have many contaminations, such as metal inserts, stickers, different plastic types connected to the housings (such as buttons), etc.

Despite these aspects, it is assumed that the plastic housings are collected as such without contaminations. The following average disassembly times are measured: 120 seconds for the portable CD players (many small screws) and around $200 \mathrm{sec}$ onds for both the faxes and audio systems. The weight of the plastic housings recycled are on average: $130 \mathrm{~g}$ for the portable CD players (ranging from 80 to $160 \mathrm{~g}$ ); $1.3 \mathrm{~kg}$ for the fax machines (ranging from 1.0 to $1.9 \mathrm{~kg}$ ) and $4.1 \mathrm{~kg}$ for the audio systems (front and back covers ranging from 2.3 to $5.1 \mathrm{~kg}$ ).
The results for the plastic recycling scenarios are visualized in the eco-efficiency graph of Fig. 14. In this graph the economic and environmental performance is displayed per $\mathrm{kg}$ of product in order to exclude the big differences in weight between the plastic dominated products. It shows that a distinction should be made in the results.

1) Large Plastic Housings: The first group of points (on the left) in this Fig. 14 reflects the scenarios for the average audio system. The first arrow represents the change in environmental and economic performance of incineration without energy recovery toward incineration, including energy recovery of the residue fraction (including almost all of the plastics within the products). The third point is the difference between incineration with energy recovery and the exclusion of the plastic housings of this operation by applying plastic recycling. This change is visualized with the second arrow. The two arrows on the left show that for the large housings some environmental improvement is realized against small extra costs per $\mathrm{kg}$ (there is a move to the right). In this, the disassembly costs are taken into account for the plastic recycling. For most of the CRT or LCD-containing appliances, disassembly is required to remove the picture tubes and the plastic housings acquired separately at (allocated) zero costs. To be more precise: plastic recycling of large encasings including disassembly costs, under best case conditions, leads to an environmental gain of $150 \mathrm{mPts} / €$ invested. (From $56 \mathrm{mPts}, € 0.37$ per kg; $1227 \mathrm{mPts}, € 7.10$ per product to $64 \mathrm{mPts}, € 0.43$ per $\mathrm{kg}$; $1447 \mathrm{mPts}, € 8.57$ per product). Plastic recycling, without taking into account disassembly costs, leads in almost all cases to vectors in the first quadrant of Fig. 2, and thus to a positive eco-efficiency.

2) Medium Sized Plastic Housings: The right group of three points in Fig. 14 reflects the scenarios for the average fax machine. The first arrow, again, represents the change in environmental and economic performance of incineration without energy recovery toward incineration including energy recovery 


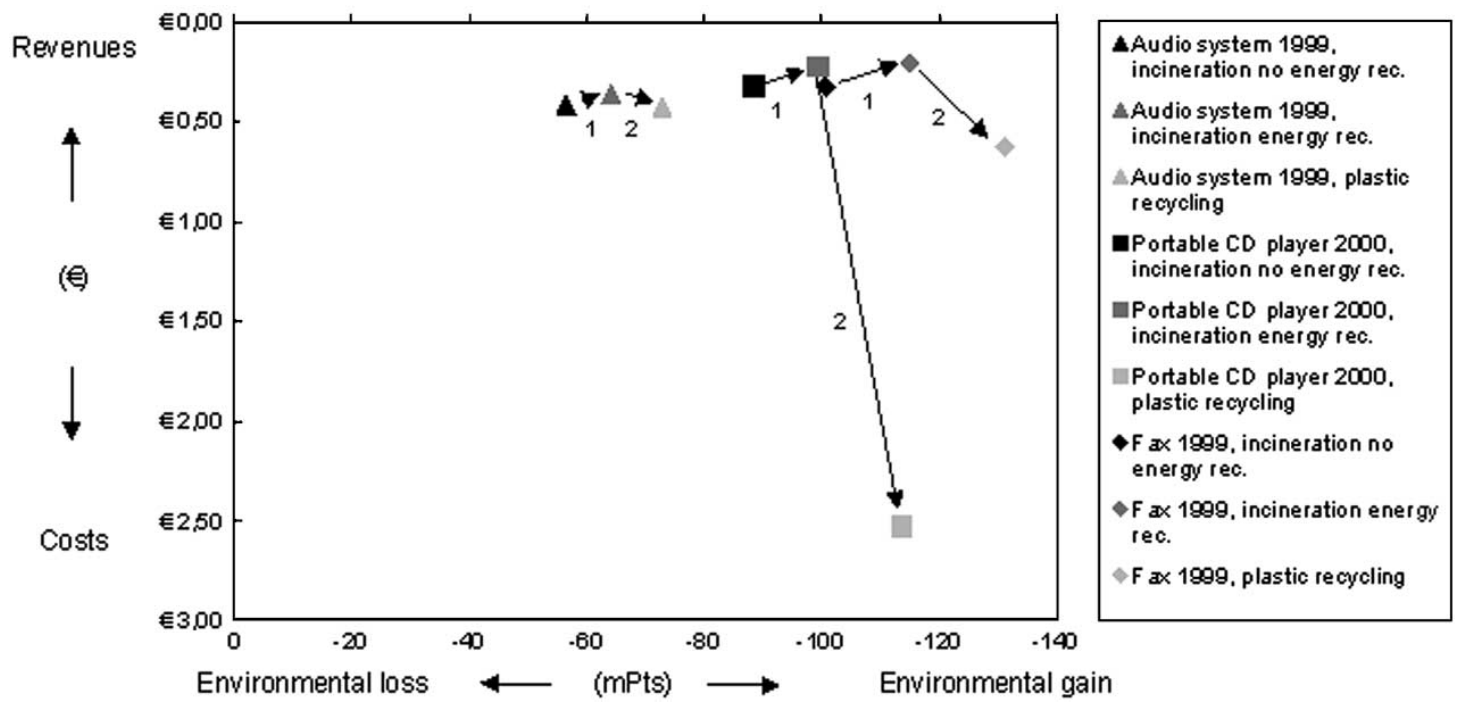

Fig. 14. Eco-efficiency per kg of plastic recycling different plastic dominated products.

of all plastics. The second arrow represents the difference between incineration with energy recovery of all plastics and the plastic recycling of the housings. The two arrows together on the right show that, for the medium sized housings, environmental improvement is realized against relatively higher costs per kg compared to the audio systems. This means that plastic recycling of medium sized encasings $(1.3 \mathrm{~kg})$ under best case conditions leads to an environmental gain of $40 \mathrm{mPts} / €$ invested (an increase from $115 \mathrm{mPts} / \mathrm{kg}$ to $131 \mathrm{mPts} / \mathrm{kg}$ and from $€ 0.21$ to $€ 0.63$ per $\mathrm{kg}$ ).

3) Small Plastic Housings: The middle group of three points in Fig. 14 reflects scenarios for the average portable CD player. The second arrow represents the difference between incineration with energy recovery of all plastics and the plastic recycling of the housings. The two arrows together on the right show that for the small plastic housings, environmental improvement is realized against high costs per $\mathrm{kg}$. This means that plastic recycling of small encasings $(0.13 \mathrm{~kg})$ under best case conditions leads to an environmental gain per amount of money invested of $6 \mathrm{mPts} / €$ invested (an increase from 99 $\mathrm{mPts} / \mathrm{kg}$ to $113 \mathrm{mPts} / \mathrm{kg}$ and from $€ 0.22$ to $€ 2.52$ per $\mathrm{kg}$ ).

\section{Eco-Efficiency of Metal Dominated Products}

The third product category to be evaluated is that of the metal dominated products. As examples, 38 different LCD projectors, CD recorders, VCRs, DVD players, and DVD recorders are used. The differences in functionality are very small inside the individual product groups. However, there are main differences in weight: The LCD projectors are from the year 2000 and weigh in between $5.0 \mathrm{~kg}$ and $8.9 \mathrm{~kg}$ (4 pieces). The VCRs are from the years 1999 (4 pieces) and 2000 (5 pieces) and are between $2.1 \mathrm{~kg}$ and $4.8 \mathrm{~kg}$. The DVD players are from the years 2001 (15 pieces) and 2002 ( 3 pieces) and are in the range of 2.0 to $3.8 \mathrm{~kg}$. The last group are the DVD recorders from the year 2002 (7 pieces). In this case, the difference in product composition and degree of product development is large, which results in differences in weight of $2.6 \mathrm{~kg}$ toward $6.6 \mathrm{~kg}$. The differences in plastic content are relatively large: The plastic content in the
CD recorder and VCRs is much higher than in the DVD, DVDR, and LCD projectors. The amount of high-integrated PWBs is the highest for the DVDR and LCD projectors resulting in higher precious metal contents.

A central question for the metal dominated products is whether dedicated shredding and separation of these products would lead to increased eco-efficiency performance. This improvement option is based on applying dedicated settings for shredding and separation in order to get more PWB materials in the copper fraction. Due to the lower plastic content of metal dominated products, no plastic fraction or residue fraction is obtained, only an aluminum, ferro, and copper fraction. Only some larger plastic pieces are separated by handpicking. The resulting more contaminated copper fraction should lead to higher amounts of materials recovered without too much dilution of these most valuable materials. The eco-efficiency of this technical improvement option is determined in relation to the default state-of-the-art recycling scenario.

The results for the dedicated shredding and separation scenarios on all products mentioned above are displayed in the eco-efficiency graph of Fig. 15. In this graph, the economic and environmental performance is displayed per $\mathrm{kg}$ of product in order to exclude the big differences in weight.

1) CD Recorders: The first two points (arrow nr. 1) represent the result for the average CD recorders. The dedicated shredding and separation does not result in higher environmental recoveries and less costs, but to the opposite effect. In this case, by sending more plastics and other environmentally relevant materials to the copper smelter with a relatively bad flue gas cleaning, it results in lower environmental gains, whereas in the original scenario more plastics are incinerated in a MSW incineration plant with a more extended and more modern flue gas cleaning system and energy recovery. The net effect is relatively small (only $5 \mathrm{mPts}$ less environmental gain and $€ 0.04$ extra costs per $\mathrm{kg}$ ), although more valuable metals are recovered in this scenario.

2) LCD Projectors: The second group of two points visualizes the change of state-of-the-art recycling toward dedicated 


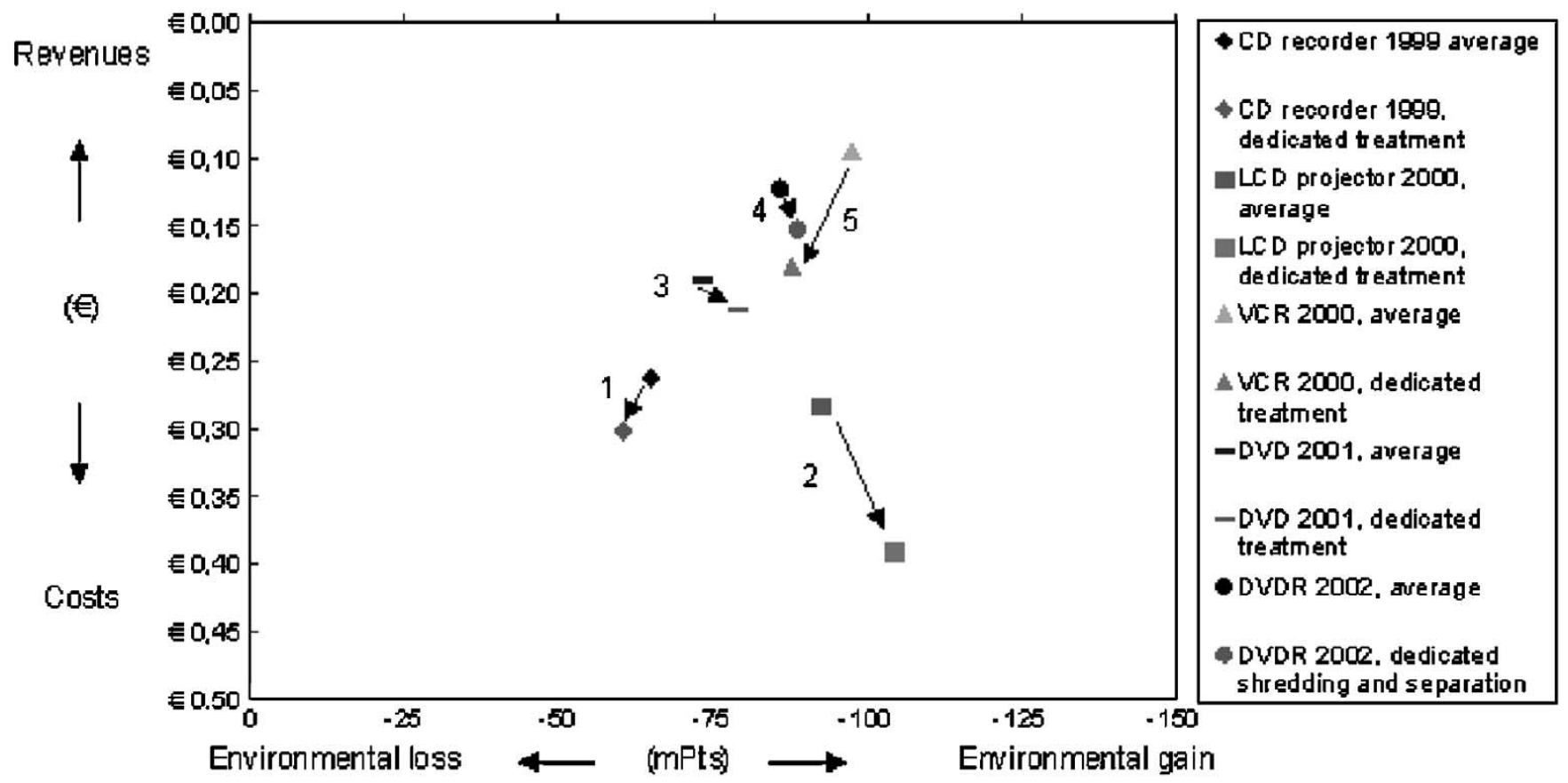

Fig. 15. Eco-efficiency per kg of dedicated shredding and separation of metal dominated products.

shredding and separation for the LCD projectors (arrow nr. 2). In this case, the metal and precious metal content is relatively high and the plastic content is low compared to the previous VCR example. For the LCD projector, the resulting eco-efficiency direction is presented with the second arrow. There is a cost increase from $€ 0.28$ to $€ 0.39$ per $\mathrm{kg}$, but in this case some environmental improvement is realized as well (around $140 \mathrm{mPts} / €$ ). The reason is that the environmental effect of recovering more valuable materials is higher than the changing impacts of incineration of plastics in a copper smelter.

3) DVD Players: The third two points in Fig. 15 represent the DVD players (arrow nr. 3). In this case, however, there is a small environmental improvement of $6 \mathrm{mPts} / \mathrm{kg}$ against a small cost increase of $€ 0.02$ (300 $\mathrm{mPts} / €$ ). However, the arrow in Fig. 15 is relatively small. Due to the low plastic content in comparison with the CD recorder, the effect of increased recovery is more or less in balance with the lower revenues due to dilution of valuable materials.

4) DVD Recorders: The same counts for the DVD recorders (arrow nr. 4). Although in this case the increase in integral costs is higher due to the higher precious metal and ferro content: The environmental gain is increased with only $3 \mathrm{mPts} / \mathrm{kg}$ against increased costs of $€ 0.03$ (around $100 \mathrm{mPts} / €$ ). The direction is quite similar, but the vector is much smaller compared to the LCD projectors.

5) VCRs: The fifth set of points is showing the results for the VCRs (arrow nr. 5). Like the CD recorders, a relatively high plastic content is also present in this case. This also leads to the same negative eco-efficiency direction as derived before for the CD recorders: $9 \mathrm{mPts} / \mathrm{kg}$ less environmental recovery and $€ 0.09 / \mathrm{kg}$ higher costs.

From the results above it can be concluded that the improvements in environmental terms are not very large compared to the effects measured for plastic recycling of large housings in the previous section. At most, in some cases a fourth quadrant result is appearing. In Section 5.2 the result of the improvement options for all product categories are compared.

\section{E. Eco-Efficiency of Precious Metal Dominated Products}

In this section, the last product category to be evaluated is that of the precious metal dominated products. For this category, two groups of products are evaluated: The cordless DECT phones from 1999 (4 pieces) and the cellular phones from 1999 (5 pieces). Chemical analysis of all PWB of all phones is individually available while the precious metal content can be very different for phones with the same age and functionality. For the cellular phones, the precious metal contents are between $320 \mathrm{ppm}$ and $385 \mathrm{ppm}$ for gold and between 187 and $222 \mathrm{ppm}$ for palladium. This is much lower compared to the $500 \mathrm{ppm}$ gold and 800 ppm palladium for the other cellular phones (high-end cellular phones from 2001 at the right in Fig. 15). The precious metal content of the cordless phones varies even more: from $8 \mathrm{ppm}$ to $183 \mathrm{ppm}$ for gold and from $23 \mathrm{ppm}$ to $135 \mathrm{ppm}$ for palladium.

This graph shows similar trends for all product types. The plastic recycling leads in all cases to almost no extra environmental gain but relatively high extra costs. The separate sorting and treatment scenario leads in all cases to an increased environmental performance. But for the products with lower precious metal contents (the cordless phones), it leads to slightly increased integral costs. This is due to the much higher logistic costs, which were included. In the cellular phone cases, an increase in economic performance is also realized. As discussed earlier, the increase in revenues for products with a relatively high precious metal content is quite substantial (from $€ 8.87$ to $€ 10.72$ per $\mathrm{kg}$ for the high-end 2000 phones and from $€ 3.69$ to $€ 4.17$ per $\mathrm{kg}$ for the 1999 low-end cellular phones). It should 


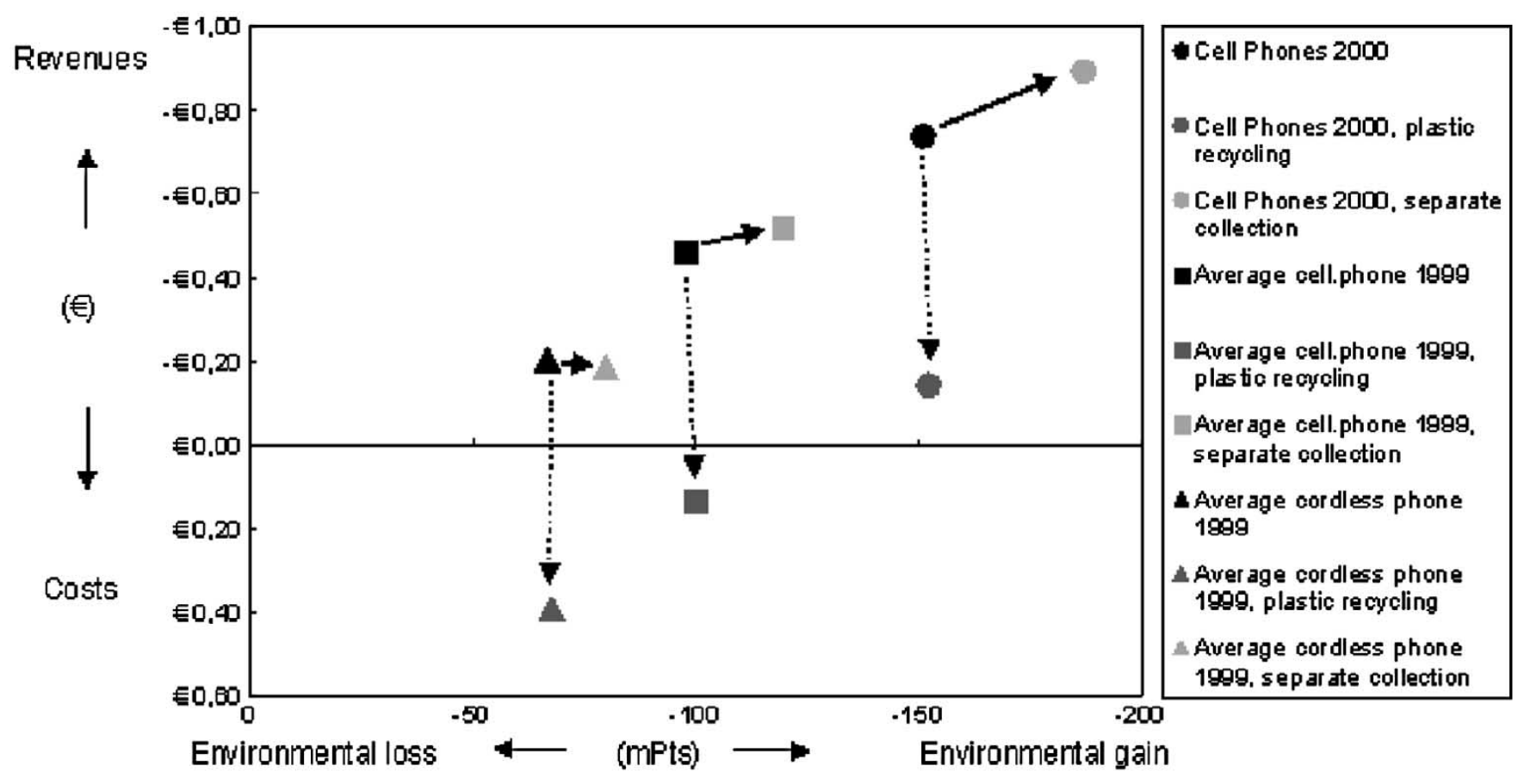

Fig. 16. Eco-efficiency per piece for precious metal dominated products.

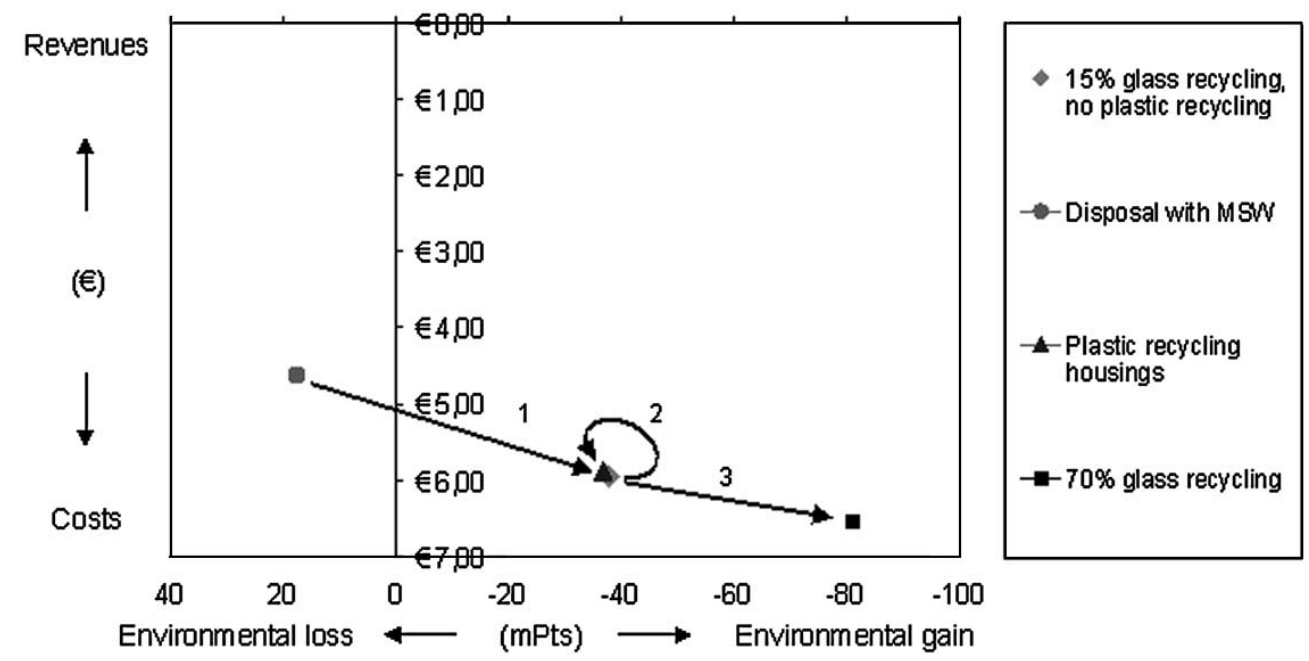

Fig. 17. Eco-efficiency of a glass dominated products (EDIP'96).

be noted that the underlying assumptions have a significant influence on the results. For the plastic recycling scenario, one of the main assumptions is an optimized product design to make plastic recycling technically possible. For the separate sorting and treatment scenario, it means that economies of scale must be realized. In simple words: enough precious metal dominated products must be collected (batches of a few tons) to make it attractive to treat them separately and to make it efficient to be shipped to a copper smelter.

\section{DisCUSSION AND CONCLUSIONS}

\section{A. Discussion}

In order to check the results generated with the Eco-Indicator'99 method, as mentioned in Section II-D3, the eco-efficiency results for the example products are also calculated under the EDIP'96 method [14] as a completely different LCA method. In Fig. 17, the comparison is made with the eco-efficiency results for the 17-in monitor under the Eco-Indicator'99, as previously illustrated in Fig. 10. Both graphs show similar results for the scenarios: increase of collection rates and glass recycling, but different results for plastic recycling.

All scenarios work out in a similar way compared to the Eco-Indicator'99 method, except for plastic recycling. This is explained by the lack of resource depletion factors for plastics in the EDIP'96 method compared to the Eco Indicator'99. This leads to almost no bonuses for preventing new primary material extraction for plastics and, as a result, to a lower evaluation of plastic recycling. It is known from [9] that the choice of the environmental assessment model does not significantly influence the results for the other product examples. Only plastics and plastic recycling are valuated very differently under various 
LCA methods [6], [14]. Under five other environmental assessment models, it appears that plastics recycling results in less environmentally beneficial outcomes compared to the Eco Indicator' 99 method.

In addition to this, other parameters having substantial influence on the results are as follows.

1) Economies of Scale: This plays an important role for glass and especially for the plastic recycling scenarios. Costs for plastic recycling can be significantly higher when applied on relatively small streams.

2) Disassembly Times: There is a large variety in disassembly times measured. In the cases of plastic recycling of small and medium sized housings, which are comparable in terms of functionality, this has the highest contribution to the cost increases.

3) Technical Constraints: Many of the plastic recycling cases are not possible in practice due to technical boundaries: the presence of flame-retardants, attachments with other plastic types, stickers, buttons etc., that are jeopardizing the operations.

4) Sorting and Separation Costs: In the case of separate sorting and treatment of precious metal dominated products, this aspect is highly uncertain and also dependent on return behavior of consumers, bottom-of-the-drawer effects, and refurbishment in other markets.

5) Precious Metal Contents: These can vary significantly. Further research on this matter for more modern products with a higher degree of miniaturization is recommended.

\section{B. Conclusion}

1) Eco-Efficiency Directions: Summarized, the eco-efficiency directions obtained in Sections 3 and 4 can be divided into directions to be avoided, to be balanced, and to be encouraged, representing, respectively, the first quadrant, the second plus fourth quadrant, and the third quadrant of Fig. 2. These results are independent, except for plastic recycling, of the environmental assessment model chosen. Based on the results in Section 4, including a few results of similar analyses in [9], the following eco-efficiency can be divided in the four quadrants of Fig. 3.

Eco-efficiency directions to be encouraged (first quadrant) are as follows.

- The increase in collection rates of precious metal dominated products. Collection and treatment is costing less than the environmental and economic value being recovered.

- Separate sorting of precious metal dominated products with relatively high precious metal contents under the assumptions that economies of scale can be realized.

- Increase collection rates of metal dominated products with relatively high precious metal and low plastic content.

- Plastic recycling of large sized housings already disassembled (only under Eco Indicator'99 method, see the discussion in Section V-A.

Eco-efficiency directions to be balanced (second and fourth quadrant) are presented in Table IV. In this table, the results under the EDIP'96 method are also presented.
TABLE IV

FOURTH QUADRANT STRATEGIES: BALANCE

\begin{tabular}{llll}
\hline & Strategy & $\begin{array}{l}\text { El '99 } \\
\text { mPts/€ }\end{array}$ & $\begin{array}{l}\text { EDIP'96 } \\
\text { mPts' } \epsilon\end{array}$ \\
\hline 1 & Increase collection metal dominated products & $>800$ & $>100$ \\
\hline 2 & $\begin{array}{l}\text { Separate collection precious metal dominated } \\
\text { products with relatively low precious metal content }\end{array}$ & $600-800$ & $80-100$ \\
\hline 3 & Increase glass recycling $15 \%$ to $70 \%$ & $380-420$ & $65-75$ \\
\hline 4 & Increase collection rates glass dominated products & $200-400$ & $30-60$ \\
\hline 5 & $\begin{array}{l}\text { Dedicated shredding and separation metal } \\
\text { dominated products with low plastic content }\end{array}$ & $50-250$ & $8-40$ \\
\hline 6 & Plastic recycling medium sized housings & $50-150$ & N.A.: 3rd quadrant \\
\hline 9 & Plastic recycling small sized housings & $2-20$ & N.A.: 3rd quadrant \\
\hline
\end{tabular}

Eco-efficiency directions to be avoided (third quadrant) are as follows.

- Dedicated shredding and separation of metal dominated products with a relatively high plastic content. This result is also independent of which environmental assessment model is chosen and only caused by a worsening in balance between recovering more material versus diluting the most valuable materials.

- Incineration of plastic and residue fractions without energy recovery.

2) Methodology: QWERTY: The QWERTY concept takes into account the environmental value of the treated secondary materials, including the level of re-application and the connected environmental burden of end-of-life treatment. The double ensemble issue of Section II-D2 and all other descriptions of end-of-life processing involved are addressed. Application of the concept shows how well the primary environmental goals of take-back and end-of-life treatment, reduction of material depletion, controlling potential toxicity, and reducing emissions are achieved in actual environmental terms. In some cases, the environmental results are not in line with the intended regulations. The example of the 17-in CRT monitor shows its added value by quantifying the influence of changes in technology in order to increase environmental performance of end-of-life treatment of consumer electronics.

The main characteristics of this concept are as follows (not all are shown in this paper [9]):

- The contribution of individual materials and material fractions to the total environmental performance of products.

- The consequences for individual stakeholders to the overall system performance are described, as well as the avenues through which they can increase end-of-life system performance.

- The consequences of system organization by visualizing the impact in the result of logistics, collective versus individual systems, collection rates, etc.

- The relation between certain policy or legislative actions and the resulting environmental performance and economic effects.

- It is based on current best available insights in science and LCA on environmental accounting and it enables fast and streamlined assessments, based on precooked environmental and economic data sets to avoid time consuming activities for evaluation of individual products. Therefore, data on all relevant processes are integrated. 
3) Methodology: QWERTY/EE): Generally, it can be concluded that addressing costs and revenues in relation to environmental costs and revenues on a quantitative way is a powerful approach for rethinking on the eco-efficiency of the end-of-life of consumer electronic products. Furthermore, better insights into the system performance and the demands and constraints of secondary material processors are obtained. Despite the uncertainties in economic data, due to the use of very specific and actual data, a good view on the current performance of the Dutch take-back system and the consequences of the enactment of the WEEE Directive is obtained. The QWERTY/EE methodology is proven to be very useful in evaluating the environmental and economic performance of products in end-of-life processing and in determining the most promising technical improvement options. With the example product, the relevance for economy and environment is also shown for all relevant end-of-life scenarios possible. With the QWERTY/EE methodology the following aspects can be addressed in a quantitative way:

- monitoring of the environmental and economic performance of individual materials, single products, and product groups within certain take-back systems;

- the environmental and economic performance of single products in different end-of-life scenarios;

- the determination of priorities regarding different materials and end-of-life options.

In addition to this, the following issues can also be addressed [9]:

- monitoring of the eco-efficiency of take-back systems as a whole;

- the quantification of the contribution of different actors and stakeholders.

\section{Consequences for Waste Policies and Stakeholder Debates}

The application of the QWERTY/EE approach in stakeholder debates can be very useful, and when followed and implemented, it is expected to lead to better end-of-life system performance in general. In most cases, consensus on which environmental assessment model to use or which priorities to assign to the different environmental themes is not required while all arrows point in the same direction. However, upfront agreement on which environmental assessment method to start with for evaluation purposes is recommended. The use of weight-based recyclability targets in the WEEE Directive [4] and the treatment rules (which currently can be fulfilled with manual disassembly only) of its Annex II leads to an overemphasis on aspects of the end-of-life chain that are of relatively less importance. Generally speaking, most environmental attention should be given to the relation between recyclers creating the right fractions for the right secondary processors who are closing material loops with these fractions. Also, attention should be given to the realization of economies of scale and efficient collection infrastructures. The exact policy measures or steps to take, especially for the options displayed with the fourth quadrant, need special attention. These can be supported by calculations as made in this paper. For instance, when an evaluation round is performed-scheduled a few years after implementation of the WEEE Directive-the QWERTY/EE methodology, the underlying calculation schemes, and the background data presented in this paper would be the appropriate means to do this.

Generally, it can be concluded that addressing economical costs and revenues in relation to environmental costs and revenues on a quantitative way is a powerful concept in rethinking about the eco-efficiency of the end-of-life of consumer electronic products.

\section{REFERENCES}

[1] A. M. M. Ansems and L. Feenstra, "Ontwikkeling verwerking afgedankte electronica, sluiten van zware metalen kringlopen,", Apeldoorn, The Netherlands, Report R2002/194, May 2002. TNO Environment, Energy and Process Innovation (in Dutch).

[2] A. M. M. Ansems, R. N. van Gijlswijk, and J. Huisman, "End of life control and management of heavy metals out of electronics," in Proc. of the 2002 Int. Symp. of Electronics and the Environment, San Francisco, CA, 2002.

[3] C. B. Boks, "The relative importance of uncertainty factors in product end-of-life scenarios, a quantification of future developments in design, economy, technology and policy," Ph.D. thesis, Delft Univ. of Technol., Apr. 2002.

[4] Official Journal of the European Union, Feb. 13, 2003. Directive 2002/95/EC of the European Parliament and of the Council on the restriction of the use of certain hazardous substances in electrical and electronic equipment (RoHS).

[5] Official Journal of the European Union, Feb. 13, 2003. Directive 2002/96/EC of the European Parliament and of the Council on waste electrical and electronic equipment (WEEE).

[6] M. Goedkoop, “The Eco Indicator'95, Final Report,” Nat. Reuse Waste Res. Prog., Amersfoort, The Netherlands, Rep. 9523, 1995.

[7] M. Goedkoop and R. Spriensma, "The Eco Indicator'99, a Damage-Oriented Method for Life Cycle Impact Assessment," Nat. Reuse Waste Res. Prog., Pré Consultants, Amersfoort, The Netherlands, Final Rep.

[8] R. Heijungs, J. B. Guinee, G. Huppes, R. M. Lankrijer, A. M. M. Ansems, and P. G. Eggels, Environmental Life Cycle Assessment of Products: Guide and Backgrounds. Leiden, The Netherlands: CML University, 1992.

[9] J. Huisman, "The QWERTY/EE concept, quantifying recyclability and eco-efficiency for end-of-life treatment of consumer electronic products," Ph.D. thesis, Delft Univ. of Technol., Delft, The Netherlands, May 2003.

[10] J. Huisman and A. L. N. Stevels, "Eco-efficiency considerations on the end-of-life of consumer electronics," in Proc. 2002 IEEE Int. Symp. on Electronics and Environment, San Francisco, CA, pp. 59-64.

[11] J. Huisman, C. B. Boks, and A. L. N. Stevels, "Quotes for environmentally weighted recyclability (QWERTY)," Int. J. Production Res., vol. 41, no. 16, pp. 3649-3665.

[12] "Multiple Environmental Benchmarks 1998-2003," Philips Consumer Electronics, Environmental Competence Centre, Eindhoven, The Netherlands.

[13] R. Spriensma, C. Alvarado, and M. Goedkoop, "LCA Soldering Materials," Rep. Philips and Alpha Fry Technology, Amersfoort, The Netherlands, Feb. 2002

[14] H. Wenzel, M. Hauschild, and L. Alting, Environmental Assessment of Products, London, U.K.: Chapman \& Hall, 1997, vol. 1. methodology, tools and case studies in product development.

[15] A. L. N. Stevels, "Eco-efficiency of take back systems of electronic products," in Proc. of the 1999 IEEE Int. Symp. on Electronics and the Environment, Danvers, MA, pp. 286-291.

[16] I. Stobbe, "Meeting data requirements by using the IZM/EE toolbox for a screening assessment of the environmental impacts of electronic products," presented at the 2001 Eur. Conf. on Electronics and the Environment: Improving the Environmental Performance in Electronics Supply Chains, Oslo, Norway.

[17] S. Zhang, E. Forssberg, J. van Houwelingen, P. Rem, and L. Y. Wei, "End-of-life electric and electronic equipment management toward the 21 st century," in Waste Management Res. 2000, Nr. 18, U.K., 2000, pp. $73-85$. 


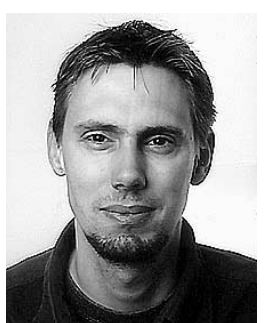

Jaco Huisman received the M.S. degree in chemical engineering from Eindhoven University of Technology, Eindhoven, The Netherlands in 1999, and the $\mathrm{Ph} . \mathrm{D}$. degree from Delft University of Technology, Faculty of Design, Construction and Production, Design for Sustainability Program, in 2003, with the thesis entitled "The QWERTY/EE concept, Quantifying recyclability and eco-efficiency for end-of-life treatment of consumer electronic products."

Currently, he is continuing his work at Delft University of Technology as a Postdoc in commission of the Dutch Ministry of Environment, Philips Consumer Electronics-Environmental Competence Centre, and NVMP (Dutch take-back system for electronic waste).

Dr. Huisman received two best paper awards for publications in IEEE conference proceedings. He received one for Environmentally Weighed Recycling Quotes-Better Justifiable and Environmentally More Correct at the Proceedings of the 2000 IEEE International Symposium on Electronics and the Environment, San Francisco,USA, in May 2000. He also received one for the paper Balancing Design Strategies and End-of-Life Processing for the Ecodesign 2003 conference, Tokyo, Japan, in December 2003.

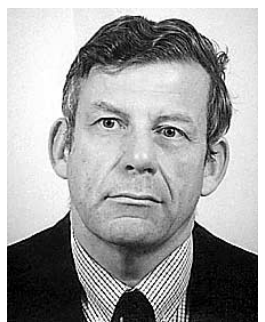

Ab L. N. Stevels studied chemical engineering at the Technical University of Eindhoven, Eindhoven, The Netherlands, and received the Ph.D. degree (cum laude) in physics and chemistry from Groningen University, Groningen, The Netherlands, in 1969.

As of September 1969, he has worked for Royal Philips Electronics in a manifold of capacities in research on materials, production technology of glass, as a business manager in electro optics, and as a project manager for joint ventures and licenses in Asia. In January, 1993, he became a Senior Advisor in Environment at the Environmental Competence Center of Philips Consumer Electronics. In December 1995, He was appointed as a part-time Professor in Environmental Design at Delft University of Technology. In the fall of 1999, he was Visiting Professor in the Mechanical Engineering Department of Stanford University, in the fall of 2001 he was Visiting Pprofessor at the Faculty of Electrical Engineering of the Technical University Berlin (TU Berlin), Berlin, Germany, in 2002 he was visiting the School of Industrial Systems Engineering at Georgia Institute of Technology, Atlanta, and in 2003 the Industrial Ecology Program at NTN University in Trondheim, Norway. His main research interests include how to make Eco-design into day-to-day business really happen and has researched in detail the setting up of take-back and recycling systems for electronics. For these purposes, tools and management procedures have been developed which have proven their strength through their practical success. He is the author of some 140 journal articles and conference contributions. These training courses on applied Eco design have been held at various universities (Delft, Stanford, TU Berlin, TU Vienna, SurreyArts, Mexico City, Hong Kong Poly, and NTNU), Philips departments and divisions around the globe and at other companies.

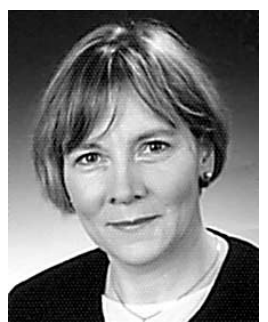

Irina Stobbe studied mathematics at the Math-Mech. Faculty of the St. Petersburg University, St. Petersburg, Russia, until 1977. She received the Ph.D. degree in natural sciences (Dr. rer.-nat.) with a thesis on properties of vibration systems in gears from the Academy of Sciences, Berlin, Germany, in 1990.

She worked at the Research Institutes for Mechanics and Automatization at the Academy of Sciences in Berlin and at the Fraunhofer Institute for Informatics and Data Processing, Karlsruhe and Berlin. There, she developed software for vibrations and optical inspection systems, among this the Laboratory Information Management System ERAD for acquisition and archiving of sample and measuring data in laboratories and collaborated in environmental analysis. With the special interests in recycling and reuse of electronic parts, she has developed an automated disassembly line for printed wired boards to study process properties and quality questions on boards and components for reuse. Currently, she is with the Technical University Berlin, Research Center for Microperipheric Technologies, providing research in the European EFSOT project, concerning life cycle tasks of lead free electronics, marking of products for environment related issues, and knowledge management approaches in project communities. She collaborated with the Environmental Engineering Department of the Fraunhofer Institute for Reliability and Microintegration (IZM), Berlin, in development of assessment tools for design for environment.

Dr. Stobbe is a member of the VDI, the Association of Engineers and is engaged in FIB, making the engineers profession interesting for young women. She is active in education: 1997-1999 for Information Management and Statistics at the Berlin Institute for Analytics and Environment (BIFAU). She takes part in the circular lectures on Design of Environmental sound Electronic Products at the Technical University Berlin since 1999. In 2003/2004 she was appointed as an Assistant Professor in Knowledge Management and in Knowledge Based Systems at the University of Applied Sciences (FHTW) in Berlin. 